OPEN ACCESS

Edited by:

Md. Abu Bin Hasan Susan, University of Dhaka, Bangladesh

Reviewed by:

Md Kalam,

Texas A\&M University Texarkana,

United States

Md Arifuzzaman

Clemson University, United States

*Correspondence:

Agnes Schulze

agnes.schulze@iom-leipzig.de

Specialty section: This article was submitted to

Polymer Chemistry,

a section of the journal

Frontiers in Chemistry

Received: 29 October 2021 Accepted: 20 December 2021

Published: 18 January 2022

Citation:

Schmidt M, Abdul Latif A, Prager A, Gläser $R$ and Schulze A (2022) Highly

Efficient One-Step Protein

Immobilization on Polymer Membranes

Supported by Response

Surface Methodology.

Front. Chem. 9:804698

doi: $10.3389 /$ fchem.2021.804698

\section{Highly Efficient One-Step Protein Immobilization on Polymer Membranes Supported by Response Surface Methodology}

\author{
Martin Schmidt ${ }^{1}$, Amira Abdul Latif ${ }^{1}$, Andrea Prager ${ }^{1}$, Roger Gläser ${ }^{2}$ and Agnes Schulze ${ }^{1 *}$ \\ ${ }^{1}$ Leibniz Institute of Surface Engineering (IOM), Leipzig, Germany, ${ }^{2}$ Institute of Chemical Technology, Leipzig University, Leipzig, \\ Germany
}

Immobilization of proteins by covalent coupling to polymeric materials offers numerous excellent advantages for various applications, however, it is usually limited by coupling strategies, which are often too expensive or complex. In this study, an electron-beambased process for covalent coupling of the model protein bovine serum albumin (BSA) onto polyvinylidene fluoride (PVDF) flat sheet membranes was investigated. Immobilization can be performed in a clean, fast, and continuous mode of operation without any additional chemicals involved. Using the Design of Experiments (DoE) approach, nine process factors were investigated for their influence on graft yield and homogeneity. The parameters could be reduced to only four highly significant factors: BSA concentration, impregnation method, impregnation time, and electron beam irradiation dose. Subsequently, optimization of the process was performed using the Response Surface Methodology (RSM). A one-step method was developed, resulting in a high BSA grafting yield of $955 \mathrm{mg} \mathrm{m}^{-2}$ and a relative standard deviation of $3.6 \%$. High efficiency was demonstrated by reusing the impregnation solution five times consecutively without reducing the final BSA grafting yield. Comprehensive characterization was conducted by $\mathrm{X}$-ray photoelectron spectroscopy (XPS), Fourier-transform infrared spectroscopy (FTIR), and measurements of zeta potential, contact angle and surface free energy, as well as filtration performance. In addition, mechanical properties and morphology were examined using mercury porosimetry, tensile testing, and scanning electron microscopy (SEM).

Keywords: surface modification, polymer membrane, serum albumin, radiation-induced graft immobilization, electron beam, response surface methodology

\section{INTRODUCTION}

Membrane technology is used in many modern applications such as water treatment (Pendergast and Hoek, 2011), biomedicine (Casimiro et al., 2019), pharmaceutical industry (Buonomenna and Bae, 2014), or in chromatography (Zeng and Ruckenstein, 1999). Polymer-based membrane filters dominate the multi-billion global membrane module market with a share of $92.1 \%$ (Sutherland, 2004). Polyvinylidene fluoride (PVDF) is among the most widely used materials due to excellent features such as chemical resistance, high thermal stability and mechanical strength. Thus, products prepared from PVDF are widely used in many areas (Feng et al., 2013; Kang and Cao, 2014). However, fluoropolymers have the severe disadvantage of being highly hydrophobic facilitating 
adsorption of organic compounds and thus, fouling (Liu et al., 2011). Surface modification of membranes has been investigated extensively in order to modify the surface hydrophilicity (Subasi and Cicek, 2017), introduce advanced functionalities (Nasef, 2004), or improve blood compatibility (Mollahosseini et al., 2020). Many methods have been studied, of which protein grafting is a widely used approach (Fang et al., 2010; Zhu et al., 2011; Liu et al., 2012; Riyasudheen et al., 2012; Wang et al., 2012; Wu et al., 2014; Akashi and Kuroda, 2015; Mayuri et al., 2020).

Bovine serum albumin (BSA) is a globular protein derived from cow serum (molecular weight $\mathrm{M}_{\mathrm{W}}=66.5 \mathrm{kDa}$ ). BSA is a commonly used biomolecule in research due to its wide availability, low cost and similarity to human serum albumin (Majorek et al., 2012). Furthermore, BSA is a carrier protein for a degradation product of hemoglobin, i.e., bilirubin, with multiple binding sites per BSA molecule (Blauer and King, 1970), as well as for other substances such as drugs (Bi et al., 2009), or toxic compounds (Das et al., 2017). Hence, BSA has been immobilized and used as a functional biopolymer for various applications, e.g., 1) for the improvement of blood compatibility (hemocompatibility) in blood filtration systems (Zhang et al., 2013); 2) for the reduction of hemolysis in blood storage devices (Li et al., 2014); 3) for the adsorption of bilirubin in the treatment of the liver disease hyperbilirubinemia via hemoperfusion ( $\mathrm{Wu}$ et al., 2018); 4) for the removal of bacteria, dyes and proteins by water filtration membranes (Ahmad Khairuddin et al., 2018); or 5) for the generation of high-speed humidity sensors in conjugation with multiwall carbon nanotubes (Bhattacharya and Sasmal, 2016).

Immobilized proteins are used in industry and medicine due to several advantages such as convenient handling in continuous processes, prevention of product contamination, or improved stability towards changing process conditions. There are a variety of immobilization methods in order to attach proteins onto polymer surfaces, including physical adsorption, entrapment, or covalent attachment (Eş et al., 2015). The latter is the defining result of the well-established polymer surface grafting (Horie et al., 2004; Ulbricht, 2006; Szymczyk et al., 2019). Covalent immobilization is often preferred to achieve stable and high protein coverage, and to avoid delamination (Kato et al., 2003). In case of inert PVDF, however, no polar reactive sites are present, which further impairs covalent coupling. For this reason, the surface must first be activated, e.g., via reactive reagents (Yiğitoğlu et al., 2007), plasma treatment (Kochkodan and Sharma, 2012), or ionizing radiation (Ramos-Ballesteros et al., 2019). Subsequently, a wet-chemical coupling reaction might be carried out to bind the biomolecules (Schulze et al., 2017; Schmidt et al., 2018). Nevertheless, the methods published so far have considerable drawbacks that are diametrically opposed to future industrial applications (Kang et al., 1993; Ladavière et al., 1999; Fang et al., 2009; Fang et al., 2010; Zhu et al., 2011; Liu et al., 2012; Riyasudheen et al., 2012; Wang et al., 2012; Zhang et al., 2013; Li et al., 2014; Wu et al., 2014; Akashi and Kuroda, 2015; Vitola et al., 2015; Wu et al., 2018; Mayuri et al., 2020): 1) modifications are performed in multi-step batch reactions; 2) often require several expensive or toxic coupling chemicals like acrylates, carbodiimide, or glutaraldehyde; 3) take many hours up to several days to complete; 4) involve harsh reaction conditions; or 5) are limited to selected types of polymer substrates. Therefore, protein-modified polymer materials still fall short of their true potential due to a lack of cost-effective and highly scalable manufacturing strategies.

In the last decade, a novel approach for polymer membrane surface grafting was developed (Schulze et al., 2010). Recently, a new terminology for this kind of polymer processing was proposed, i.e., radiation-induced graft immobilization (RIGI) (Schmidt et al., 2021). Briefly, a membrane impregnated with an aqueous solution of a modifying compound is irradiated by an electron beam (EB) produced via an electron accelerator. The polymer, as well as the solutes are activated and react immediately with each other by forming covalent bonds. In contrast to the traditional radiation-induced graft polymerization (RIGP), RIGI can utilize non-vinyl compounds such as small organic stable molecules (e.g., glycerin, malonic acid, or glucose) (Schulze et al., 2012), hydrophilic polymers (Schulze et al., 2013), photoactive molecules (Müller et al., 2018), enzymes (Starke et al., 2013; Jahangiri et al., 2014), or antimicrobial peptides (Reinhardt et al., 2018), instead of potentially hazardous vinyl monomers like acrylates (Suh et al., 2018), or styrenics (Gibbs and Mulligan, 1997). Since the processing is very fast and straightforward, a continuous mode of operation for industrial roll-to-roll applications is feasible (Supplementary Figure S1A in SI). Furthermore, due to the direct coupling by using solely the polymer and an aqueous solution of the modifying agent, this approach becomes highly environmentally friendly, clean and thus "green."

Response surface methodology (RSM) is a statistical and mathematical tool introduced in 1951 (Box and Wilson, 1951), which is often used for the optimization of processes or reactions. RSM is part of a larger statistical toolbox for experimentation, i.e., Design of Experiments (DoE). Compared to the conventional experimental approach, known as one-factor-at-a-time (OFAT), the DoE approach probes the entire parameter space using systematically distributed points in order to fit the measurement data with a mathematical model (Supplementary Figure S1B in SI). This multifactorial method has many advantages (Anderson and Whitcomb, 2010), including 1) reducing the number of experiments and costs; 2) rapidly generating reliable experimental data; 3) reducing numerical noise; or 4) determining effect sizes and, in particular, interactions between parameters. RSM has been applied in the field of polymer grafting in some studies (Chung et al., 2014; Madrid et al., 2017; Mandal et al., 2017; Ganj et al., 2019; Vatanpour and Sanadgol, 2020), and was also successfully applied to electron-beam-induced grafting of vinyl monomers by the Nasef group (Nasef et al., 2011; Nasef et al., 2012; Nasef et al., 2013; Nasef et al., 2014).

In this study, a highly efficient method for coupling the protein BSA to PVDF polymer membranes using EB irradiation was investigated. The aim was to develop a one-step approach providing high BSA grafting yields while reducing experimental costs, such as BSA amount, time, or irradiation dose, without compromising filtration performance. First, the 

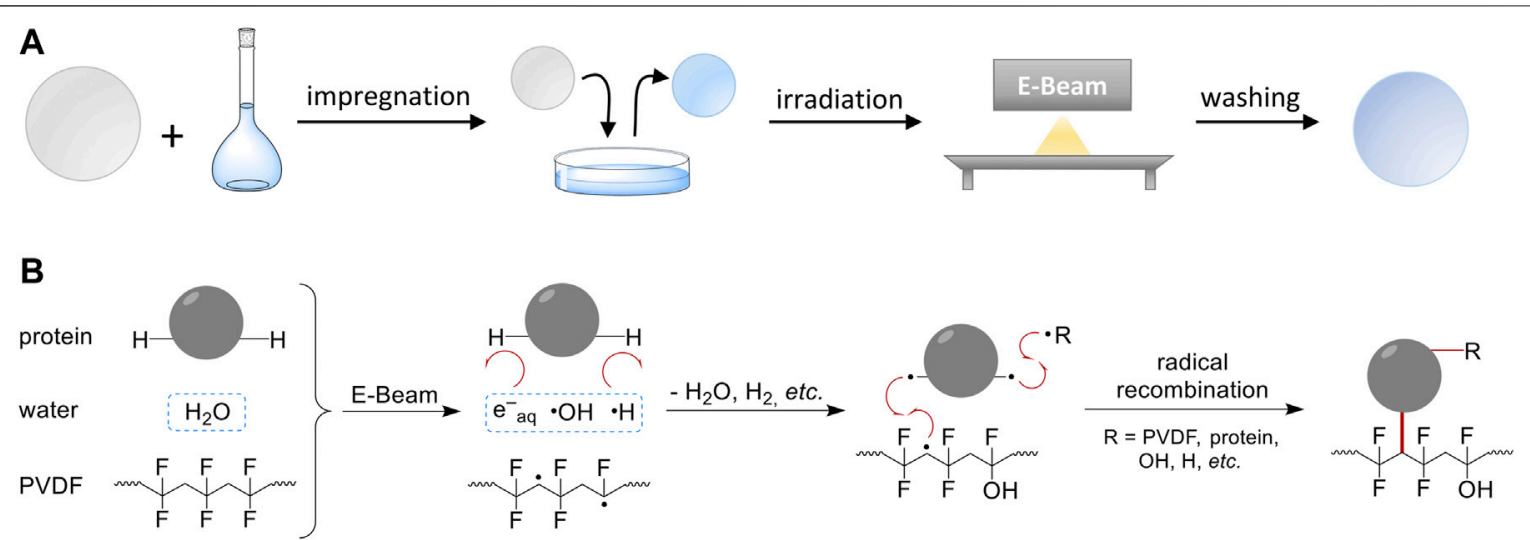

FIGURE 1 IScheme of the general method and proposed reaction mechanism. (A) The RIGI process solely utilizes a polymer membrane and an aqueous solution of the modifying compound (here: BSA). The membrane is impregnated with the aqueous solution. In case of hydrophobic polymers, a pre-wetting step has to be included. Finally, irradiation with electron beam and washing is performed. (B) Simplified scheme of the proposed reaction mechanism according to recent studies (Schmidt et al., 2021). Electron beam irradiation results in the formation of active species such as PVDF mid-chain radicals, and water radiolysis products, primarily solvated electrons, $\mathrm{OH}$ radicals, and $\mathrm{H}$ radicals. Due to its low abundance $(\omega \leq 2 \%)$, the radiation chemistry of the protein is of minor importance. Immediately, water radiolysis products react with the solute, e.g., via $\mathrm{H}$ abstraction, to form protein radicals. Finally, radical recombination reactions lead to covalent coupling between protein molecules and polymer chains.

process was characterized in terms of the amount and homogeneity of grafted BSA using a high number of nine process factors and a Minimum-Run Resolution V (MR5) design. Significant parameters were subsequently used to optimize the procedure applying the RSM approach. Models as well as optimized settings were confirmed, and modified membrane samples were extensively characterized, and discussed with respect to literature.

\section{MATERIALS AND METHODS}

\subsection{Materials}

Commercially available polyvinylidene fluoride flat sheet microfiltration membrane (PVDF; ROTI ${ }^{\circledR}, 0.45 \mu \mathrm{m}$ ) was purchased from Carl Roth (Karlsruhe, Germany). Bovine serum albumin stock solution (BSA, mass fraction of $\omega=30 \%$ in saline) was obtained from Sigma Aldrich (St. Louis, United States). Triton ${ }^{\circledR}$ X-100 washing detergent and ethanol (EtOH, absolute) was purchased from Merck (Darmstadt, Germany). BSA quantification was performed using a commercial assay (Pierce ${ }^{\text {TM }}$ BCA Protein Assay Kit) from Thermo Scientific (Rockford, IL, United States). Deionized water in Millipore ${ }^{\circledast}$ quality was used for all steps. All chemicals were of analytical grade and used without further purification.

\subsection{BSA Immobilization}

\subsubsection{General Procedure}

The general procedure of this EB-induced graft immobilization as well as the proposed mechanism is given in Figure 1. By using the DoE approach, nine parameters (factors) were determined and systematically investigated within defined limits (factor levels). The first step was the impregnation of a PVDF membrane $(\varnothing=47 \mathrm{~mm})$ with an aqueous solution of BSA. Subsequently, the impregnated membrane was removed from the impregnation solution and irradiated by EB. Irradiation was performed in $\mathrm{N}_{2}$ atmosphere with $\mathrm{O}_{2}$ quantities $<15 \mathrm{ppm}$ in a self-built lowenergy electron accelerator. The voltage and conveyor speed were $160 \mathrm{kV}$ and $2.1-3.0 \mathrm{~m} \mathrm{~min}^{-1}$, respectively. An irradiation dose was applied by adjusting the beam current from 0-20 mA. Directly after EB irradiation, a washing step at $450 \mathrm{rpm}$ was performed to remove non-covalently attached molecules $\left(10 \mathrm{~min}, \omega=0.5 \%\right.$ Triton $\mathrm{X}-100,4 \times 10 \mathrm{~min} \mathrm{H}_{2} \mathrm{O}$ in excess). Finally, the modified membrane samples were dried over night at $37^{\circ} \mathrm{C}$ and used for further characterization. The nine process factors are given in Table 1.

\subsubsection{MR5 Design}

To reduce this large number of potential factors, first, a characterization of the EB process was performed in order to retain only the vital few ones. For this purpose, statistics software Design-Expert 13 (Stat-Ease, Minneapolis, MN, United States), and a Minimum-Run Resolution V (MR5) characterization design were applied (Table 2) (Whitcomb and Anderson, 2004). The MR5 design provides information on main effects, as well as two-factor interactions (2FI). By choosing this design, the number of experiments could be reduced from $512\left(2^{9}\right.$ for a full 2-level factorial design) to only 46 experimental runs. The responses examined were 1) the final immobilized BSA amount after washing (BSA grafting yield, GY) as the average of five measurement points (see characterization section); 2) the standard deviation (SD); and 3) the relative standard deviation (RSD) of the GY as a measure of homogeneity. Signal-to-noise ratio $(\mathrm{S} / \mathrm{N})$ values were derived from historical data and used to calculate power in Design-Expert. Power is a statistical measure for the ability of the design to detect significant effects 
TABLE 1 | Investigated nine process factors for the EB-based graft immobilization of BSA on PVDF.

\begin{tabular}{|c|c|c|}
\hline Factor & Name & Description/Comment \\
\hline A & BSA concentration & BSA solutions were freshly prepared each time from stock solution $\left(\omega=30 \%\right.$, or $\left.B \approx 300 \mathrm{~g} \mathrm{~L}^{-1}\right)$ \\
\hline $\mathrm{B}$ & temperature of BSA & simulation of protein storage conditions by using tempered solvents for preparing BSA solutions \\
\hline C & impregnation time & adsorption and potential enrichment of BSA on the PVDF polymer membrane \\
\hline D & impregnation volume & amount of BSA solution added to the PVDF membrane located in a plastic Petri dish \\
\hline$E$ & irradiation dose & dose of the EB irradiation by adjusting the beam current of the electron accelerator \\
\hline $\mathrm{F}$ & impregnation method (1-step) & $\begin{array}{l}\text { addition of EtOH to the BSA solution in order to enable wettability of the hydrophobic membranes (a mass fraction of } \omega= \\
30 \% \text { is at least necessary, as shown in Supplementary Figure } \mathbf{S} 2 \text { in SI) }\end{array}$ \\
\hline G & impregnation method (2-steps) & $\begin{array}{l}\text { hydrophobic nature of PVDF requires a pre-wetting step ( } 1 \mathrm{~min} \mathrm{EtOH}, 5 \times 5 \mathrm{~min} \mathrm{H}_{2} \mathrm{O} \text { in excess to exchange EtOH) prior to } \\
\text { the actual impregnation with aqueous BSA solution }\end{array}$ \\
\hline $\mathrm{H}$ & shaking conditions & shaking of the Petri dish using a platform shaker (Vibramax 100, Heidolph, Schwabach, Germany) \\
\hline J & surficial drying & $\begin{array}{l}\text { irradiation of impregnated membranes either wet, or partially dried (by placing them in laboratory tissue and applying a roller } \\
\text { to remove surficial liquid spots, which could affect homogeneity) }\end{array}$ \\
\hline
\end{tabular}

TABLE 2 | Investigated nine process factors by using a MR5 characterization design. Factors can be divided in numerical and categoric types (here: presence or absence, yes or no). Given are the factor simplified names (see Table 1), units, and each a low factor level (coded as -), and a high factor level (coded as +), respectively. The factor levels were chosen to cover a practical range of common settings of this EB processing method. The MR5 design resulted in 46 experimental runs.

\begin{tabular}{|c|c|c|c|c|c|c|}
\hline Factor & Name & Units & Type & $\begin{array}{c}\text { Low level } \\
(-)\end{array}$ & $\begin{array}{c}\text { High level } \\
(+)\end{array}$ & Comment \\
\hline$A$ & BSA & $g L^{-1}$ & Numeric & 1 & 10 & Corresponds to $\omega=0.1 \%$, or $\omega=1 \%$ \\
\hline $\mathrm{B}$ & Temperature & ${ }^{\circ} \mathrm{C}$ & Numeric & 10 & 20 & Storage in refrigerator, or at room temperature \\
\hline $\mathrm{C}$ & Time & $\min$ & Numeric & 0.1 & 10 & Impregnation time of $6 \mathrm{~s}$, or $10 \mathrm{~min}$ \\
\hline $\mathrm{D}$ & Volume & $\mathrm{mL}$ & Numeric & 5 & 15 & Impregnation volume \\
\hline$E$ & Dose & kGy & Numeric & 20 & 200 & Irradiation dose of EB \\
\hline $\mathrm{F}$ & $\mathrm{EtOH}$ & $y / n$ & Categoric & no & yes & Yes: impregnation solution with $\mathrm{EtOH}(\omega=30 \%)$ \\
\hline$G$ & Pre-wetting & $y / n$ & Categoric & no & yes & Yes: prior pre-wetting step of pristine membrane \\
\hline $\mathrm{H}$ & Shaking & $y / n$ & Categoric & no & yes & Yes: shaking at $450 \mathrm{rpm}$ on a platform shaker \\
\hline J & Drying & $y / n$ & Categoric & No & yes & Yes: surficial drying prior to EB irradiation \\
\hline
\end{tabular}

(Supplementary Table S1 in SI). After collecting all response measurement data, the design was analyzed by using analysis of variance (ANOVA) for each response. The model was reduced by selecting only terms with a $\mathrm{p}$-value $\leq 0.01$, i.e., highly significant terms, in order to reduce the number of model terms. Eventually, the final model is obtained according to Eq. 1 via multiple linear regression

$$
y=\beta_{0}+\beta_{1} x_{1}+\beta_{2} x_{2}+\beta_{12} x_{1} x_{2}+\ldots+\varepsilon
$$

where: $y$ is the response; $x_{i}$ is the process factor; $\beta_{i}$ is the model parameter; and epsilon, is the random error or noise. Various diagnostics provided by Design-Expert were considered in order to statistically validate the model. Furthermore, the subsequent optimization via RSM is used to provide a more accurate model of the vital few factors. Finally, the model was confirmed by performing five additional runs for two sets (factor levels: all low; and all high) and comparing the average to calculated prediction intervals (PI).

\subsubsection{RSM Design}

The MR5-based characterization resulted in a reduced number of significant factors (see results section), which were used for optimization with RSM and Design-Expert 13. Initially, a
Central Composite Design (CCD) was chosen. Center points were replicated six times to estimate the prediction capability, and 14 non-center points were performed including factorial points, as well as axial points to cover extreme factor combinations. The CCD was randomized, rotatable $(\mathrm{k}=1.68179)$, and employed a reduced cubic model. Investigated factors included three numeric parameters, and a refined categoric factor for the overall impregnation method, i.e., either utilizing only a pre-wetting step, or only EtOH addition instead of pre-wetting. Examined

TABLE 3 | Investigated process factors of I-optimal RSM design. Given are the simplified names (see Table 1), units, and each a lowest, and highest factor level limit, respectively. Please note, the categoric factor 'method' was introduced as combination of the two previous factors describing possible impregnation methods, i.e., preceding pre-wetting step, or addition of $\mathrm{EtOH}$ to the impregnation solution.

\begin{tabular}{lllccc} 
Factor & Name & Units & Type & Lower limit & Upper limit \\
\hline A & BSA & $\mathrm{g} \mathrm{L}^{-1}$ & numeric & 1.0 & 18.4 \\
B & time & min & numeric & 0.1 & 12.4 \\
C & dose & kGy & numeric & 20 & 234 \\
\hline D & method & - & categoric & 1-step (EtOH) & 2-steps (pre-wetting)
\end{tabular}


responses were the same as in the MR5 design (Supplementary Table S1 in SI). Upon evaluation, a significant lack-of-fit (LOF) test was observed, implying that there is a higher model that can better describe the data. For this reason, the initial CCD design was augmented resulting in additional 15 runs ( 7 for the model, three for LOF test, three replicates, and two additional points). The final RSM design was thus converted to an I-optimal design with a cubic model and a total of 55 experimental runs. Moreover, factor levels were adjusted to a lowest and a highest limit (Table 3). The design itself was evaluated using the fraction of design space (FDS) tool. An FDS score of $84 \%(\mathrm{~S} / \mathrm{N}=2)$, or $97 \%$ $(\mathrm{S} / \mathrm{N}=3)$, respectively, proved a high quality of the design to be used for optimization (Supplementary Figure S3 in SI). The data was analyzed using ANOVA and processed as described earlier. After a reduced model was obtained, optimized settings for specific criteria (see results section) were calculated using Design-Expert, and finally, confirmed by running five replicate runs for each optimized method.

\subsection{Characterization}

\subsubsection{Quantification of BSA Grafting Yield}

After performing all experimental runs of a design, the amount of BSA grafted onto the membrane was calculated as the grafting yield (GY; $\mathrm{mg} \mathrm{m}^{-2}$ ) employing

$$
G Y=\frac{w_{g}}{A}
$$

where $w_{g}$ is the weight of the protein grafted onto the membrane, and $A$ is the surface area. The GY as main response was determined by using a commercial assay based on bicinchoninic acid (BCA, Pierce protein assay) (Smith et al., 1985). Briefly, five specimens of $\varnothing=10 \mathrm{~mm}$ were stamped out from each dried PVDF sample $(\varnothing=47 \mathrm{~mm}, 1 \mathrm{x}$ center, $4 \mathrm{x}$ offcenter, see Supplementary Figure S4A in SI), placed into a 48well microplate, and were incubated with $300 \mu \mathrm{L}$ of BCA reagent for $30 \mathrm{~min}$ at $300 \mathrm{rpm}$ in an oven $\left(37^{\circ} \mathrm{C}\right)$. Subsequently, $200 \mu \mathrm{L}$ of the reacted solution was transferred to a 96-well microplate within $5 \mathrm{~min}$ and measured at $562 \mathrm{~nm}$ in a microplate reader (Infinite ${ }^{\circledast}$ M200, Tecan, Groedig, Austria). The average (BSA GY, response $\mathrm{R} 1$ ), the standard deviation ( $\mathrm{SD}$, response $\mathrm{R} 2$ ), and the relative standard deviation (RSD, response R3) were calculated $(n=5)$. Calibration curves were generated using BSA standards from the assay kit. It should be noted that due to the hydrophobic nature of PVDF, some corrections must be applied: Calibration must be performed in the presence of pristine membrane samples to account for adsorption of the dye. In addition, there was a distinct difference if the membrane was pre-wetted before addition of the BSA standard since more protein will be distributed within the inner membrane area and thus, might be less accessible to the BCA reagent. In the case of process characterization (MR5), however, there were samples that were not pre-wetted at all, so that two separate calibration curves were created (Supplementary Figure S4B in SI).

The chemical composition of pristine and modified PVDF membranes was investigated by X-ray photoelectron spectroscopy (XPS, AXIS Ultra, Kratos Analytical, Manchester, UK) with a monochromatic $\mathrm{Al} \mathrm{K}_{\alpha}$ source operated at $150 \mathrm{~W}$
(15 kV and $10 \mathrm{~mA})$. Charge compensation and correction was applied to record survey spectra $(160 \mathrm{eV}$ pass energy, $1.0 \mathrm{eV}$ resolution), and high-resolution spectra $(40 \mathrm{eV}$ pass energy, $0.1 \mathrm{eV}$ resolution), respectively. Five spots were measured and averaged (total: $n=10$; center: $n=2$; off-center: $n=8$; see Supplementary Figure S4A in SI). Since the only source for elemental $\mathrm{N}$ is expected to be the BSA macromolecule, the nitrogen atomic percentage on the grafted membrane surface measured by XPS $\left(\mathrm{A}_{\mathrm{mN}}\right)$ can be used to calculate the degree of BSA surface coverage $\left(\Gamma_{\mathrm{BSA}}\right)$ on the membrane surface according to Eq. 3 (Zhang et al., 2013): Under the condition of complete coverage of the membrane surface with BSA, a nitrogen atomic percentage of $\mathrm{A}_{\mathrm{pN}}=12.95 \%$ is assumed, based on the total atomic composition in pure BSA powder.

$$
\Gamma_{B S A}=\frac{A_{m N}}{A_{p N}} \cdot 100 \%
$$

\subsubsection{Polymer Characterization}

Modifications of the polymeric material were investigated for modified samples and for pristine PVDF reference in terms of surface wettability, functional groups, and zeta potential. Surface wettability of membranes with water, as well as diiodomethane, $\mathrm{CH}_{2} \mathrm{I}_{2}$, was determined using a static contact angle measuring system (DSA30E, KRÜSS, Hamburg, Germany), applying the sessile drop method and the Young-Laplace model. Surface free energy was determined using the Owens-Wendt-Rabel-Kaelble model (Owens and Wendt, 1969). To reduce the influence of porosity, the samples were additionally compressed with high pressure $(p=200 \mathrm{kN})$ using a hydraulic press. Measurements were performed at least in triplicate. BSA grafting was further confirmed with Fourier-transform infrared spectroscopy (FTIR) taken in ATR (attenuated total reflection) mode and as transmission spectra using the Vector 22 FTIR spectrometer (Bruker, Billerica, United States), and a diamond cell (Golden Gate Specac). Spectra were recorded in the range of $4,000-500 \mathrm{~cm}^{-1}$ at a spectral resolution of $2 \mathrm{~cm}^{-1}$. Finally, zeta potential was determined by measuring the streaming potential in an adjustable gap cell of the SurPASS system (Anton Paar, Graz, Austria) utilizing $1 \mathrm{mM} \mathrm{KCl}$ solution. Four measurements were recorded for each $\mathrm{pH}$ step.

\subsubsection{Membrane Characterization}

Membrane samples were analyzed in terms of morphology, porosimetry, mechanical properties, and water permeance according to methods described elsewhere (Schulze et al., 2013). Morphology was investigated by scanning electron microscopy (SEM, Ultra 55, Carl Zeiss Microscopy, Oberkochen, Germany). Magnifications ranged from 25- to 25,000 -fold. Samples were cut manually and then coated with a thin (ca. $20 \mathrm{~nm}$ ) chromium layer using the Z400 sputtering system (Leybold, Hanau, Germany). Pore size distribution and porosity were investigated in duplicate with a mercury intrusion porosimeter (PoreMaster 30, Quantachrome Instruments, Odelzhausen, Germany). Mechanical properties of membrane samples (Young's modulus, E, and 
tensile strength, $\mathrm{F}_{\mathrm{r}} ; n=3$ ) were determined using a tensile testing machine (inspekt mini $3 \mathrm{kN}$, Hegewald \& Peschke, Nossen, Germany). Pure water permeance $P$ was determined for samples $(\varnothing=47 \mathrm{~mm}$, active area $\mathrm{A}=$ $13.3 \mathrm{~cm}^{2}$ considering the sealing ring) from the measured permeation time $t$ for filtration of $V=200 \mathrm{ml}$ water at a pressure of $p=1$ bar using a stainless-steel filtration cell (16249, Sartorius Stedim, Göttingen, Germany). Permeance was measured in triplicate and calculated using Eq. 4

$$
P=\frac{V}{A \cdot t \cdot p}
$$

\section{RESULTS AND DISCUSSION}

\subsection{MR5 Design}

Grafting of BSA on PVDF microfiltration flat sheet membranes was achieved by an EB process (Figure 1). EB irradiation is able to activate the polymer and the solutes by generating reactive species that can immediately react with each other (Schmidt et al., 2021). To estimate individual effect sizes and two-factor interactions (2FI), a Design of Experiments approach was used applying a MR5 design integrated in statistics software Design-Expert 13. By setting a low and a high factor level for each parameter, the factor space was largely covered. The investigated main response was the final BSA grafting yield, which was determined with a protein quantification assay (BCA). Furthermore, the (relative) standard deviation, (R)SD, as a measure of graft homogeneity was also investigated. The MR5 design, i.e., combinations of factor levels and measured responses, is given in SI (Supplementary Table S2). Recently, a reaction mechanism for this radiation-induced graft immobilization (RIGI) was proposed based on computational and experimental studies of two small model molecules, glycine and taurine (Schmidt et al., 2021): Briefly, EB irradiation leads to 1) direct ionization of the organic polymer, subsequently forming reactive radical species; and 2) water radiolysis with the formation of reactive intermediates such as $\mathrm{OH}$ radicals, solvated electrons, or $\mathrm{H}$ radicals, respectively. Water radiolysis species are able to transfer dissolved compounds into radicals, e.g., via $\mathrm{H}$ abstraction reaction. Thus, radical recombination reactions between the polymer surface and solutes result in the formation of covalent bonds facilitated by close contact due to, e.g., hydrophobic or ionic interaction. We expect the same to be applied for protein immobilization, however, due to much larger size of these biomolecules, multiple covalent bonds per protein molecule could be formed facilitating the coupling process.

The MR5 design was analyzed via ANOVA. Initially, the model contained a total of 45 model terms, consisting of nine main effects (ME) and 36 two-factor interactions (2FI). The model was reduced manually with a criterion of $\mathrm{p}$-value $\leq 0.01$, in order to highly reduce the number of terms by retaining only the most significant ones. The final model included 10 model terms, consisting of $5 \mathrm{ME}$ and five 2FI (Supplementary Table S3 in SI). The model F-value of 32.98 implies the model is significant, and that there is only a chance of $p=0.01 \%$ this F-value could occur due to noise. Furthermore, quality of the model was confirmed by a high adjusted correlation coefficient of $\mathrm{R}_{\mathrm{adj} .}^{2}=0.8766$, indicating a strong correlation. Only three numerical factors (i.e., BSA concentration, A; impregnation time, $\mathrm{C}$; and irradiation dose, E), as well as two categorial factors (EtOH addition, F; and pre-wetting step, G) are statistically significant and thus, important. Please note, although the $\mathrm{p}$-value of factor $\mathrm{F}(\mathrm{EtOH}, p=0.2356)$ was above the boundary criterion, the term must be included for hierarchical reasons because $\mathrm{FG}$ (EtOH - pre-wetting) is highly significant. All numerical factors interact with each other (i.e., $\mathrm{AC}, \mathrm{AE}$, and $\mathrm{CE}$, respectively), as do the categorical ones (EF, and FG). Interestingly, neither temperature, nor impregnation volume, nor shaking, nor surficial drying showed a highly significant effect on BSA GY, indicating that the process can be simplified, and savings are possible (e.g., lower impregnation volume). The final model is given in SI (Supplementary Table S4), however, since this MR5 design is not intended for predictions but rather for process characterization, the RSM model should be used instead.

Since the GY was calculated as average of five spots for each membrane sample (i.e., experimental run), the standard deviation is a good approximation for the macroscopic homogeneity. In MR5 design, a factor space as large as possible is covered. This resulted in several factor combinations which are not suitable for the final process, however, are necessary to estimate effect sizes. Scatterplots revealed this issue, as low yields occurred more frequently (Supplementary Figure S5A in SI). This is mainly explained by low factor levels such as a BSA mass concentration of $B=1 \mathrm{~g} \mathrm{~L}^{-1}$, or a dose of $\mathrm{D}=20 \mathrm{kGy}$ [lower amounts of generated reactive species (Buxton et al., 1988)]. Furthermore, the wettability of the hydrophobic membrane with aqueous BSA solution is crucial, which can be ensured either by the addition of $\omega \geq 30 \% \mathrm{EtOH}$, and/or by performing a pre-wetting step. Moreover, due to characteristics of the BCA quantification assay, higher GY tend to produce higher SD. However, the opposite is true for RSD, which can usually reach very high values for low GY [Supplementary Figure S5B in SI, Horwitzlike relationship (Albert and Horwitz, 1997)]. For instance, run 11 resulted in a BSA grafting yield of $9.0 \mathrm{mg} \mathrm{m}^{-2}$ with $\mathrm{SD}=$ $9.5 \mathrm{mg} \mathrm{m}^{-2}$ and $\mathrm{RSD}=105.1 \%$, while run 21 resulted in a BSA grafting yield of $837.5 \mathrm{mg} \mathrm{m}^{-2}$ with $\mathrm{SD}=21.8 \mathrm{mg} \mathrm{m}^{-2}$ and $\mathrm{RSD}=$ $2.6 \%$. In consequence, this means that both responses, SD and $\mathrm{RSD}$, would lead to a distorted representation in this special case. Nevertheless, since in the final process a high BSA GY is desirable, the RSD appears to be a good indicator for homogeneity. ANOVA analysis of RSD is shown in Supplementary Table S5 in SI, exhibiting fewer model terms than ANOVA results of SD (Supplementary Table S6 in SI). For RSD, a square root transformation had to be applied, and model reduction via p-values resulted in 13 model terms, consisting of seven main effects and six 2FI. Again, impregnation volume was not significant at all, however, impregnation time seemed to have no significant influence either. The model F-value of 14.81 implies the model is significant, and that there is only a chance of $p=0.01 \%$ this F-value could occur due to noise. A correlation coefficient of $\mathrm{R}_{\mathrm{adj} .}^{2}=0.7996$ indicated a strong correlation. 

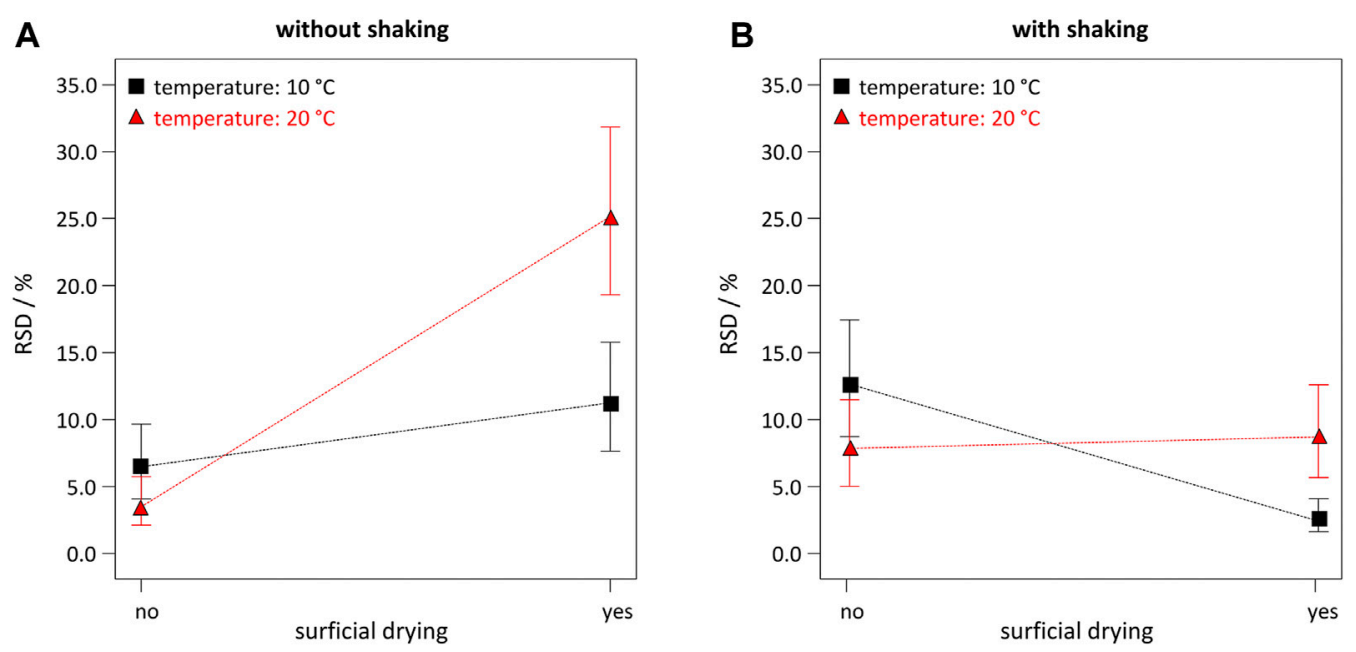

FIGURE 2 | Interaction plots for correlations between RSD and the 2FI BJ (temperature $\cdot$ drying). Plots were obtained for following settings: $\beta_{\mathrm{BSA}}=10 \mathrm{~g} \mathrm{~L}^{-1}, \mathrm{t}=10$ min, D = $200 \mathrm{kGy}$, no EtOH, with pre-wetting step, and (A) without shaking; or (B) with shaking.

In contrast to BSA grafting yield, three additional main factors (temperature, B; shaking, $\mathrm{H}$; and surficial drying, J) appeared in the model. However, all three showed high p-values of $p=0.2514$, $p=0.3701$, and $p=0.1667$, respectively. Again, for hierarchical reasons these terms had to be included due to highly significant 2FI, e.g., HJ (shaking · drying, $p=0.0002$ ), or BJ (temperature * drying, $p=0.0024)$. Best settings were chosen for the less relevant factors by exploring interaction plots (Figure 2). Interaction plots revealed non-trivial two-factor interactions, which would be very hard to determine with the traditional OFAT approach. As a low RSD is desired, either a combination of no shaking, no drying, and room temperature/cooled solvents (Figure 2A), or a combination of shaking, drying and cooled solvents (Figure 2B) has to be applied.

In summary, the most important factor was the BSA concentration during impregnation since with increasing concentration the GY tended to increase as well, and the RSD decreased. For small organic molecules like glycine and taurine, it was found that a mass fraction of $\omega=0.1 \%$ reached much better graft yields than higher or lower concentrations (Schulze et al., 2010; Schulze et al., 2012; Schmidt et al., 2021). However, in case of protein immobilization, this local optimum does not appear to be at $0.1 \%\left(1 \mathrm{~g} \mathrm{~L}^{-1}\right)$ but rather much higher $\left(\geq 10 \mathrm{~g} \mathrm{~L}^{-1}\right)$. One reason could be the size of these biomolecules, which provide a larger attack surface for water radiolysis products and could in principle lead to formation of several reactive sites per molecule. On the one hand, this could promote multiple covalent bonds between the protein and the polymer, but on the other hand, it could also lead to cross-linking of protein molecules, which has not yet been resolved. Furthermore, the GY tended to increase with irradiation dose since with increased deposited energy, the amount of radical species tend to increase as well (Samuel and Magee, 1953; Buxton et al., 1988). Moreover, a longer impregnation time led to higher grafting yields, but significant amounts of immobilized BSA could already be detected after $6 \mathrm{~s}$ of impregnation. Interestingly, impregnation time was not important for RSD and thus, homogeneity. Finally, for all responses the impregnation methods were of significant importance, allowing for the use of both, the commonly applied 2-steps and the improved 1-step method. Please note, the impregnation method is only relevant for hydrophobic polymers such as PVDF, but for hydrophilic polymers like cellulose, neither a pre-wetting step, nor addition of EtOH must be performed. Other process parameters such as solution temperature, surficial drying, or shaking were only relevant for homogeneity and could be set to best settings and thus, kept stationary for follow-up experiments. The impregnation volume showed no influence at all. Hence, in potential technological implementations, advanced impregnation processes such as spraying instead of dip coating might be feasible. For each response, a model was created in Design-Expert, and confirmed with five replicated runs for two different settings (factor levels 1) all low; and 2) all high; see Table 2). Results confirmed the MR5 models with the only exception of RSD at low factor levels (Table 4). The models are further refined by the RSM design.

\subsection{RSM Design}

The RSM design, i.e., combinations of factor levels and measured responses, is given in SI (Supplementary Table S7). According to results gained by MR5 design, the following best settings were used for ease of operation: impregnation volume $\mathrm{V}=7 \mathrm{ml}$, temperature $\mathrm{T}=20^{\circ} \mathrm{C}$, without shaking, and without drying, respectively. Response R1, BSA GY, was analyzed via ANOVA and the model was reduced manually with a criterion of $\mathrm{p}$-value $\leq 0.05$. The final model consisted of 17 terms, including (expectedly) all main effects, two-factor interactions, as well as quadratic and cubic terms (Table 5). The model F-value of 79.87 implies the model is significant, and that there is only a chance of $p=0.01 \%$ this F-value could occur due to noise. Furthermore, the quality of the 
TABLE 4 | Confirmation of response models (MR5 design). Two settings were examined (factor levels all low, and all high), and the data mean was compared to the predicted mean and the 95\% prediction interval (PI). Responses SD and RSD had to be transformed using a square root function indicated as (sqrt).

\begin{tabular}{|c|c|c|c|c|c|c|c|}
\hline Location & Analysis & Predicted mean & SD & $n$ & 95\% PI low & Data mean & 95\% PI high \\
\hline \multirow[t]{3}{*}{ all low (-) } & BSA GY & 41.6 & 112.3 & 5 & -114.7 & 7.5 & 198.0 \\
\hline & SD (sqrt) & 2.8 & 1.9 & 5 & 0.4 & 2.3 & 6.2 \\
\hline & RSD (sqrt) & 64.9 & 20.2 & 5 & 38.5 & 33.1 & 94.1 \\
\hline \multirow[t]{3}{*}{ all high (+) } & BSA GY & 885.0 & 112.3 & 5 & 737.8 & 914.6 & $1,032.2$ \\
\hline & $\mathrm{SD}$ (sqrt) & 14.6 & 4.5 & 5 & 7.6 & 21.1 & 23.0 \\
\hline & RSD (sqrt) & 12.4 & 8.6 & 5 & 1.6 & 2.3 & 28.3 \\
\hline
\end{tabular}

TABLE 5 | ANOVA results for response R1, BSA grafting yield (RSM, l-optimal design).

\begin{tabular}{|c|c|c|c|c|c|}
\hline Source & Sum of squares & Df & Mean square & F-value & p-value \\
\hline Block & $2.092 \cdot 10^{6}$ & 1 & $2.092 \cdot 10^{6}$ & - & - \\
\hline Model & $4.649 \cdot 10^{6}$ & 17 & $2.735 \cdot 10^{5}$ & 79.87 & $<0.0001$ \\
\hline A: BSA & $3.896 \cdot 10^{5}$ & 1 & $3.896 \cdot 10^{5}$ & 113.77 & $<0.0001$ \\
\hline B: time & $16,620.00$ & 1 & $16,620.00$ & 4.85 & 0.0341 \\
\hline C: dose & $14,523.90$ & 1 & $14,523.90$ & 4.24 & 0.0467 \\
\hline D: method & $88,863.16$ & 1 & $88,863.16$ & 25.95 & $<0.0001$ \\
\hline $\mathrm{AC}$ & $2.902 \cdot 10^{5}$ & 1 & $2.902 \cdot 10^{5}$ & 84.76 & $<0.0001$ \\
\hline$A D$ & 1858.84 & 1 & 1858.84 & 0.543 & 0.4660 \\
\hline $\mathrm{BC}$ & $2,415.71$ & 1 & $2,415.71$ & 0.706 & 0.4065 \\
\hline CD & $89,819.51$ & 1 & $89,819.51$ & 26.23 & $<0.0001$ \\
\hline$A^{2}$ & $2.764 \cdot 10^{5}$ & 1 & $2.764 \cdot 10^{5}$ & 80.72 & $<0.0001$ \\
\hline$B^{2}$ & $38,577.94$ & 1 & $38,577.94$ & 11.27 & 0.0019 \\
\hline $\mathrm{c}^{2}$ & $2.043 \cdot 10^{5}$ & 1 & $2.043 \cdot 10^{5}$ & 59.67 & $<0.0001$ \\
\hline$A C D$ & $32,371.55$ & 1 & $32,371.55$ & 9.45 & 0.0040 \\
\hline$A C^{2}$ & $1.663 \cdot 10^{5}$ & 1 & $1.663 \cdot 10^{5}$ & 48.56 & $<0.0001$ \\
\hline $\mathrm{B}^{2} \mathrm{C}$ & $53,124.52$ & 1 & $53,124.52$ & 15.51 & 0.0004 \\
\hline$C^{2} D$ & $77,938.43$ & 1 & $77,938.43$ & 22.76 & $<0.0001$ \\
\hline$A^{3}$ & $50,031.45$ & 1 & $50,031.45$ & 14.61 & 0.0005 \\
\hline $\mathrm{C}^{3}$ & $1.477 \cdot 10^{5}$ & 1 & $1.477 \cdot 10^{5}$ & 43.14 & $<0.0001$ \\
\hline Residual & $1.233 \cdot 10^{5}$ & 36 & $3,424.35$ & & \\
\hline Lack of Fit (LOF) & $85,167.13$ & 23 & $3,702.92$ & 1.26 & 0.3380 \\
\hline Pure Error & $38,109.51$ & 13 & $2,931.50$ & - & - \\
\hline Cor Total & $6.865 \cdot 10^{6}$ & 54 & - & - & - \\
\hline
\end{tabular}

model was confirmed by a very high adjusted correlation coefficient of $\mathrm{R}_{\text {adj. }}^{2}=0.9620$, indicating a strong correlation. Moreover, excellent prediction capability was proven by a very high prediction coefficient of $\mathrm{R}_{\text {pred. }}^{2}=0.9349$. A LOF test F-value of 1.26 implies that the LOF is not significant relative to the pure error, i.e., the model is suitable to describe the data, and there is no need to use higher order models.

In comparison to the MR5 approach, scatterplots revealed that most data points are located at higher graft yields due to elimination of inappropriate settings, e.g., lack of membrane wettability (Supplementary Figure S6A in SI). Unfortunately, both SD and RSD could not be analyzed via this RSM design because a significant LOF was detected. However, by inspecting the data scatterplots, most values were close to or below $\mathrm{RSD}=5 \%$, possibly as a consequence of the selected best settings exposed via MR5 characterization (Supplementary Figure S6B in SI). In general, higher BSA concentration and higher EB irradiation doses led to higher yields for both, 2-step method (Figures 3A,B), and 1-step method (Figures 3C,D), respectively. Interestingly, the 1-step method produced higher BSA grafting yields in average, which is unexpected at first since the addition of EtOH should dramatically decrease the concentration of water radiolysis products such as $\mathrm{OH}$ radicals due to scavenging. However, in contrast to typical $\mathrm{OH}$ scavengers like tert-butanol which produces relatively stable radicals due to sterically hindrance (Bobrowski, 2017), EtOH scavenging may result in more reactive radical species leading to further reaction cascades. Thus, the highest measured grafting yield of $1,374 \mathrm{mg} \mathrm{m}^{-2} \pm 131 \mathrm{mg} \mathrm{m}^{-2}$ was achieved in run 16 , applying $18.4 \mathrm{~g} \mathrm{~L}^{-1} \mathrm{BSA}, 6.5 \mathrm{~min}$ impregnation using the 1step method, and $150 \mathrm{kGy}$ irradiation dose. Very high doses could lead to effects such as degradation of the polymer material. Since this RIGI approach utilizes aqueous 


\section{BSA grafting yield / $\mathrm{mg} \mathrm{m}^{-2}$}

$16 \longrightarrow 1374$

A

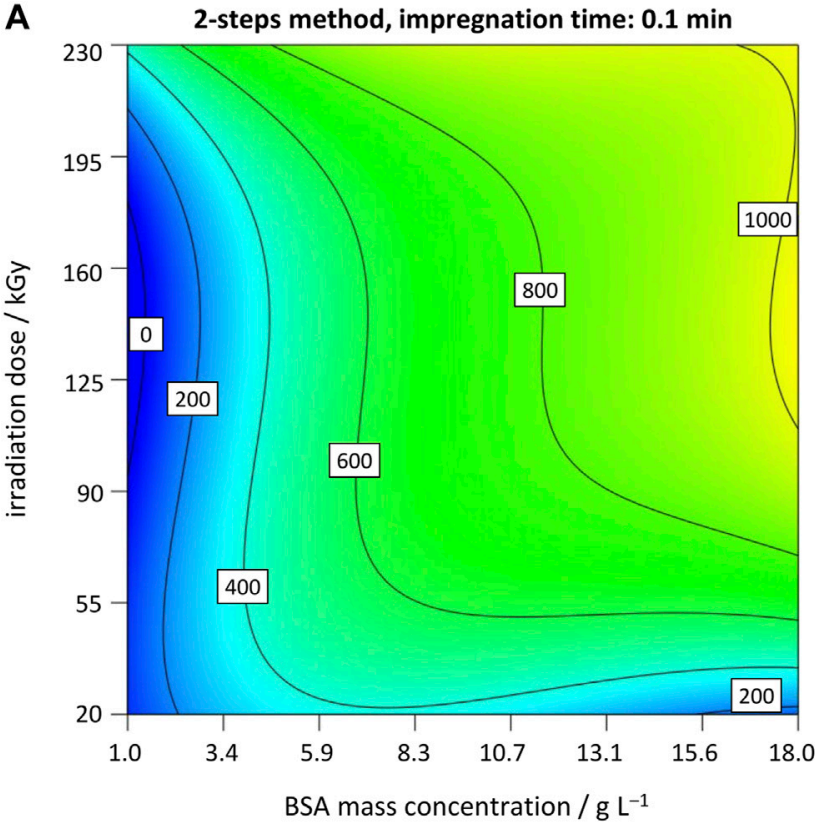

C

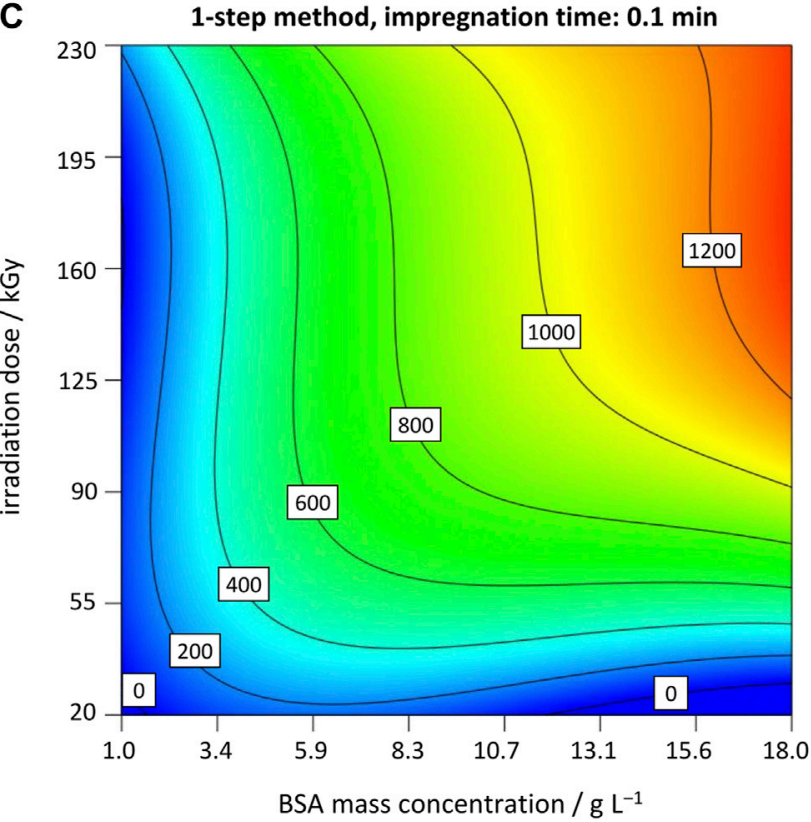

B
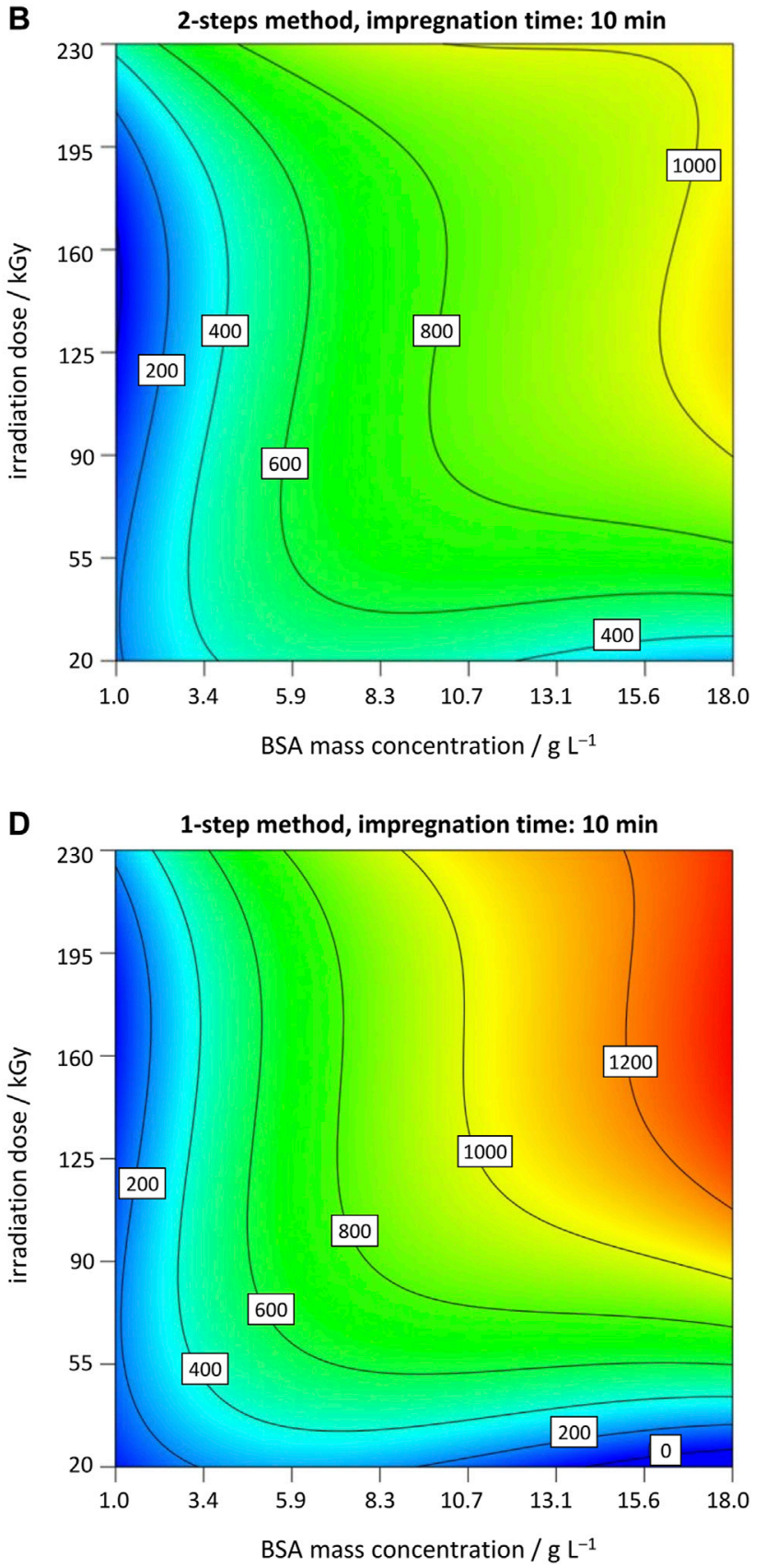

FIGURE 3 | Contour plots of response R1, BSA GY, as a function of BSA mass concentration in the impregnation solution, irradiation dose, and impregnation time, $\mathrm{t}$, for 2-steps method at $\mathbf{( A )} \mathrm{t}=0.1 \mathrm{~min} ; \mathbf{( B )} \mathrm{t}=10 \mathrm{~min}$; and for 1 -step method at $(\mathbf{C}) \mathrm{t}=0.1 \mathrm{~min} ; \mathbf{( D )} \mathrm{t}=10 \mathrm{~min}$.

impregnated membranes, the energy deposition is strongly attenuated by water molecules and thus, the membrane mechanic features are widely not affected (see analytic section). For the BSA concentration, the contour plots showed that a plateau of BSA GY is reached when using the 2-step impregnation method, but a slightly increasing trend for the 1-step method was observable. Nonetheless, further investigation has to be performed to exclude protein crosslinking. The final model for the 2-step method is given in Eq. 5, and for the 1-step method in Eq. 6, respectively. 

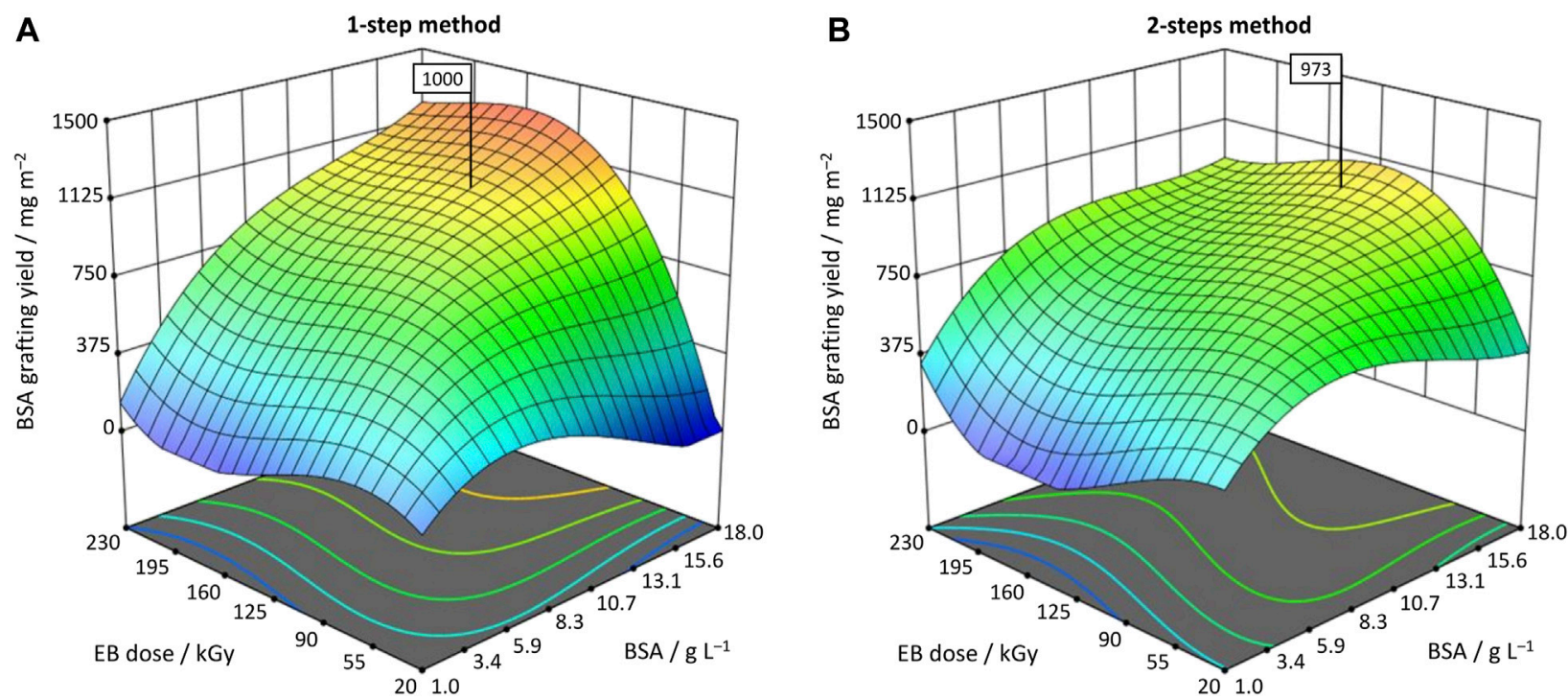

FIGURE 4 | 3D response surface plots for $(\mathbf{A})$ optimized 1-step method ( $\mathrm{t}=2.7 \mathrm{~min})$; and $\mathbf{( B )}$ optimized 2-steps method ( $\mathrm{t}=5.7 \mathrm{~min})$. The flags highlight the predicted BSA grafting yield after numerical optimization via desirability function.

2-steps method: $B S A G Y=-90.9+110.9 \cdot B S A+101.7 \cdot$ time

$$
\begin{aligned}
& +3.4 \cdot \text { dose }+1.1 \cdot B S A \cdot \text { dose }-0.6 \\
& \cdot \text { time } \cdot \text { dose }-12.5 \cdot B S A^{2}-9.0 \\
& \cdot \text { time }^{2}-0.07 \cdot \text { dose }^{2}-0.004 \cdot B S A \\
& \cdot \text { dose }^{2}+0.06 \cdot \text { time }^{2} \cdot \text { dose }+0.3 \\
& \cdot B S A^{3}+0.0003 \cdot \text { dose }
\end{aligned}
$$

1-step method: $B S A G Y=-307.6+90.5 \cdot B S A+101.7 \cdot$ time

$$
\begin{aligned}
& +8.8 \cdot \text { dose }+1.4 \cdot B S A \cdot \text { dose }-0.6 \\
& \cdot \text { time } \cdot \text { dose }-12.5 \cdot B S A^{2}-9.0 \\
& \cdot \text { time }^{2}-0.1 \cdot \text { dose } e^{2}-0.004 \cdot B S A \\
& \cdot \text { dose }^{2}+0.06 \cdot \text { time }^{2} \cdot \text { dose }+0.3 \\
& \cdot B S A^{3}+0.0003 \cdot \text { dose }
\end{aligned}
$$

A high BSA grafting yield was targeted for this RSM. But simply determining the maximum value $\left(1,374 \mathrm{mg} \mathrm{m}^{-2}\right)$ might not always be useful, as side effects such as pore clogging are not considered. Hence, other responses such as filtration performance should be included, and an optimization via desirability function could be performed. Desirability is a mathematical method to find an optimum and one of the most widely used methods for analyzing multiple responses (Derringer and Suich, 2018). For this study, an optimization via desirability was carried out using statistics software DesignExpert 13. The GY was set at a target value of $1,000 \pm 50 \mathrm{mg} \mathrm{m}^{-2}$, and at the same time the aim was to minimize the BSA mass concentration, impregnation time, and irradiation dose, respectively (Figure 4). For the 1-step method, the optimization predicted a BSA mass concentration of $\beta_{\text {opt. }}=$ $11.5 \mathrm{~g} \mathrm{~L}^{-1}$, an impregnation time of $\mathrm{t}_{\text {opt. }}=2.7 \mathrm{~min}$, and a dose of $\mathrm{D}_{\text {opt. }}=117 \mathrm{kGy}$. For the 2-steps method, predicted optimal settings were $\beta_{\text {opt. }}=14.5 \mathrm{~g} \mathrm{~L}^{-1}, \mathrm{t}_{\text {opt. }}=5.7 \mathrm{~min}$, and $\mathrm{D}_{\text {opt. }}=$ $107 \mathrm{kGy}$. Interestingly, the newly introduced 1-step method was predicted to achieve similar results with lower BSA concentration and impregnation time, reducing overall complexity and cost. Only the dose had to be set slightly higher $(\Delta=10 \mathrm{kGy})$, but this is too low to be practically relevant. Again, the models were confirmed by performing five replicates for each location. In both methods, the BSA GY mean was within the $95 \%$ prediction interval and thus, confirmed the models (Table 6). Data revealed an average BSA GY of $955 \mathrm{mg} \mathrm{m}^{-2} \pm 3.6 \%$ for the 1-step method, and $993 \mathrm{mg} \mathrm{m}^{-2} \pm$ $5.6 \%$ for the 2 -steps method, respectively. Covalency could be confirmed indirectly by comparing the adsorption reference, i.e., employing the same conditions but $0 \mathrm{kGy}: 41 \mathrm{mg} \mathrm{m}^{-2} \pm 56 \%$ for the 1-step method, and $63 \mathrm{mg} \mathrm{m}^{-2} \pm 17 \%$ for the 2 -steps method, respectively.

Finally, the reusability of the impregnation solution was investigated. A major advantage of the RIGI approach for surface modification of polymer-based membranes is the omission of coupling chemicals. Since chemically induced coupling reactions are typically carried out in batch operation, the reaction solution can usually only be used once. Especially in the case of protein immobilization, chemically induced crosslinking can occur due to the presence of numerous functional groups. Instead, in the RIGI process the reaction solution is used only for impregnation; no contamination occurs. Reusability was demonstrated by impregnating each a fresh PVDF membrane five times consecutively in the same solution (optimized 1-step conditions). Subsequently, EB irradiation and washing were performed as usual. Results for each repetition 
TABLE 6 | Confirmation of response models (RSM, I-optimal design). Two settings were examined (optimum for 1-step, and 2-steps method). The data mean was compared to the predicted mean and the 95\% prediction interval (PI). Responses SD and RSD could not be analyzed since no model could be established (see text).

\begin{tabular}{|c|c|c|c|c|c|c|c|}
\hline Location & Analysis & Predicted mean & SD & $n$ & 95\% PI low & Data mean & 95\% PI high \\
\hline \multirow{3}{*}{ 1-step: $\beta_{\mathrm{BSA}}=11.5 \mathrm{~g} \mathrm{~L}^{-1}, \mathrm{t}=2.7 \mathrm{~min}, \mathrm{D}=117 \mathrm{kGy}$} & BSA GY & 998.9 & 58.5 & 5 & 932.2 & 954.9 & $1,065.7$ \\
\hline & SD & Not analyzed & & 5 & - & 33.9 & - \\
\hline & $\mathrm{RSD}$ & Not analyzed & & 5 & - & 3.6 & - \\
\hline \multirow{3}{*}{ 2-steps: $\beta_{\mathrm{BSA}}=14.5 \mathrm{~g} \mathrm{~L}^{-1}, \mathrm{t}=5.7 \mathrm{~min}, \mathrm{D}=107 \mathrm{kGy}$} & BSA GY & 972.6 & 58.5 & 5 & 889.4 & 993.0 & $1,055.9$ \\
\hline & SD & Not analyzed & & 5 & - & 55.1 & - \\
\hline & RSD & Not analyzed & & 5 & - & 5.6 & - \\
\hline
\end{tabular}

TABLE 7 | XPS measurement data of pristine PVDF reference, and PVDF-graft-BSA modified via optimized 1 -step method $(n=10)$.

\begin{tabular}{|c|c|c|c|c|c|c|c|c|c|c|}
\hline \multirow[t]{2}{*}{ Sample } & \multicolumn{6}{|c|}{ Elemental composition/at $\%$} & \multicolumn{4}{|c|}{ Elemental ratio/\% } \\
\hline & C & $\mathbf{F}$ & 0 & $\mathbf{N}$ & $\mathbf{S}$ & $\mathrm{Si}^{\mathrm{a}}$ & F/C & $\mathrm{O} / \mathrm{C}$ & $\mathrm{N} / \mathrm{C}$ & $\mathrm{S} / \mathrm{C}$ \\
\hline PVDF-Ref, pristine & 52.69 & 44.90 & 2.14 & 0.00 & 0.00 & 0.28 & 85.2 & 4.1 & 0.00 & 0.00 \\
\hline PVDF- $g$-BSA & 65.08 & 8.47 & 15.32 & 10.14 & 0.55 & 0.44 & 13.06 & 23.53 & 15.59 & 0.84 \\
\hline & \pm 1.11 & \pm 2.42 & \pm 1.01 & \pm 0.69 & \pm 0.09 & \pm 0.17 & \pm 3.92 & \pm 1.29 & \pm 1.08 & \pm 0.13 \\
\hline
\end{tabular}

${ }^{a}$ Si appears to be an impurity from the pristine PVDF, membrane, e.g. from the manufacturing process.

TABLE 8 | Comparison of grafting yields for immobilization of BSA on different polymers. In case of multiple reported data, highest yields were noted. Given are the applied BSA mass concentration, the reaction time (for RIGl: impregnation time), as well as three kinds of grafting yield parameters. Please note, literature GY data was converted from $\mu \mathrm{g} \mathrm{cm}^{-2}$ to $\mathrm{mg} \mathrm{m}^{-2}$ to faciliate comparison (conversion factor: 10).

\begin{tabular}{|c|c|c|c|c|c|c|}
\hline Sample & $\mathrm{BSA} / \mathrm{g} \mathrm{L}^{-1}$ & Time/h & $\mathrm{GY} / \mathrm{mg} \mathrm{m}^{-2}$ & N/at $\%$ & $\Gamma_{\mathrm{BSA}} / \%$ & Ref \\
\hline PVDF-g-BSA (RIGI, avg) & $11.5^{\mathrm{b}}$ & 0.05 & 955 & 10.1 & 78.3 & This study \\
\hline PVDF- $g$-BSA (RIGI, max) ${ }^{a}$ & $18.4^{b}$ & 0.1 & 1,374 & 11.1 & 85.9 & \\
\hline PMMA-g-BSA & - & 24 & 138 & - & - & Kang et al. (1993) \\
\hline PSf-g-PAA-BSA & 10.0 & 2.5 & 93 & - & - & Ulbricht and Riedel (1998) \\
\hline PES/PANAA- $g-B S A$ & 10.0 & 7 & 309 & $9.1^{\mathrm{c}}$ & - & Fang et al. (2009) \\
\hline PES/P (AN-VP-AA)-g-BSA & 10.0 & 6 & 500 & - & - & Fang et al. (2010) \\
\hline PE/PDA-g-BSA & 1.0 & 24 & - & $11.6^{\mathrm{c}}$ & - & Zhu et al. (2011) \\
\hline PES/PVP-AA-g-BSA & 10.0 & 7 & 87 & - & - & Liu et al. (2012) \\
\hline CPES- $g-B S A$ & 40.0 & 24 & 623 & - & - & Wang et al. (2012) \\
\hline $\mathrm{PP}_{\mathrm{NWF}}-g-\mathrm{PAA}-\mathrm{BSA}$ & 1.0 & 12 & - & 9.1 & 70 & Zhang et al. (2013) \\
\hline PP-g-P (PEGMA-Co-GMA)-BSA & 10.0 & 72 & - & 2.5 & 19 & Li et al. (2014) \\
\hline PVDF-DAMP-g-BSA & 1.0 & 24 & 1,280 & - & - & Vitola et al. (2015) \\
\hline PES/PDA-g-BSA & 2.0 & 24 & - & $11.8^{\mathrm{c}}$ & - & Wu et al. (2018) \\
\hline
\end{tabular}

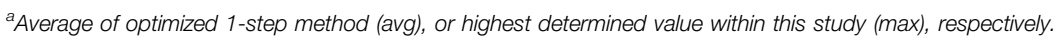

${ }^{b}$ Reusability studies showed that the impregnation solution could be used multiple times to produce $\approx 100 \%$ of initial graft yield.

${ }^{c}$ Trunk polymer consists of $N$ containing groups, which might contribute to the signal depending on BSA layer thickness.

were as followed, given in $\mathrm{mg} \mathrm{m}^{-2}$ : 1) $971 \pm 28$; 2) $946 \pm 29$; 3) $976 \pm$ 31;4) $968 \pm 26$; and 5) $951 \pm 28$. Considering the standard deviation, it was found that first, the EtOH content $(\omega=30 \%)$ was sufficient to allow multiple wetting steps. Second, about $100 \%$ of the initial GY was reproduced in each repetition proving the extraordinarily high efficiency of this method. Further studies on a continuous scale are needed to characterize the limitations of reusability.

\subsection{Characterization of Modified Membranes}

All characterizations were performed using samples produced via the optimized 1-step method. First, XPS confirmed the covalent coupling of BSA since the $\mathrm{N}$ content increased from 0 to $10.1 \% \pm$
$0.7 \%$, as well as the $\mathrm{S}$ content raised from 0 to $0.6 \% \pm 0.1 \%$ (top side, $n=10$, Table 7 ). In the center, the $\mathrm{N}$ content reached up to $11.0 \pm 0.2 \%(n=2)$, and off-center the average $\mathrm{N}$ amount was $9.9 \pm 0.6 \%(n=8)$, see Supplementary Table S8 in SI. By comparing the elemental ratio $\mathrm{F} / \mathrm{C}$, it could be shown that a BSA layer had been immobilized on the membrane surface since the ratio decreased from $85.2 \%$ (PVDF-Ref) to $13.1 \%$ (PVDF$g$-BSA). Since the average $\mathrm{N}$ amount was found to be $10.1 \%$, an average BSA surface coverage of $\Gamma_{\mathrm{BSA}}=78.3 \%$ according to Eq. 3 was calculated. For $\mathrm{N}_{\max }=11.1 \%$, the maximum BSA surface coverage was determined to be $\Gamma_{\mathrm{BSA}}=85.9 \%$. In Table 8, grafting results of this study were compared to literature data. It could be shown that the optimized grafting yield of this study is up to ten times higher than other works. To our knowledge, the highest 

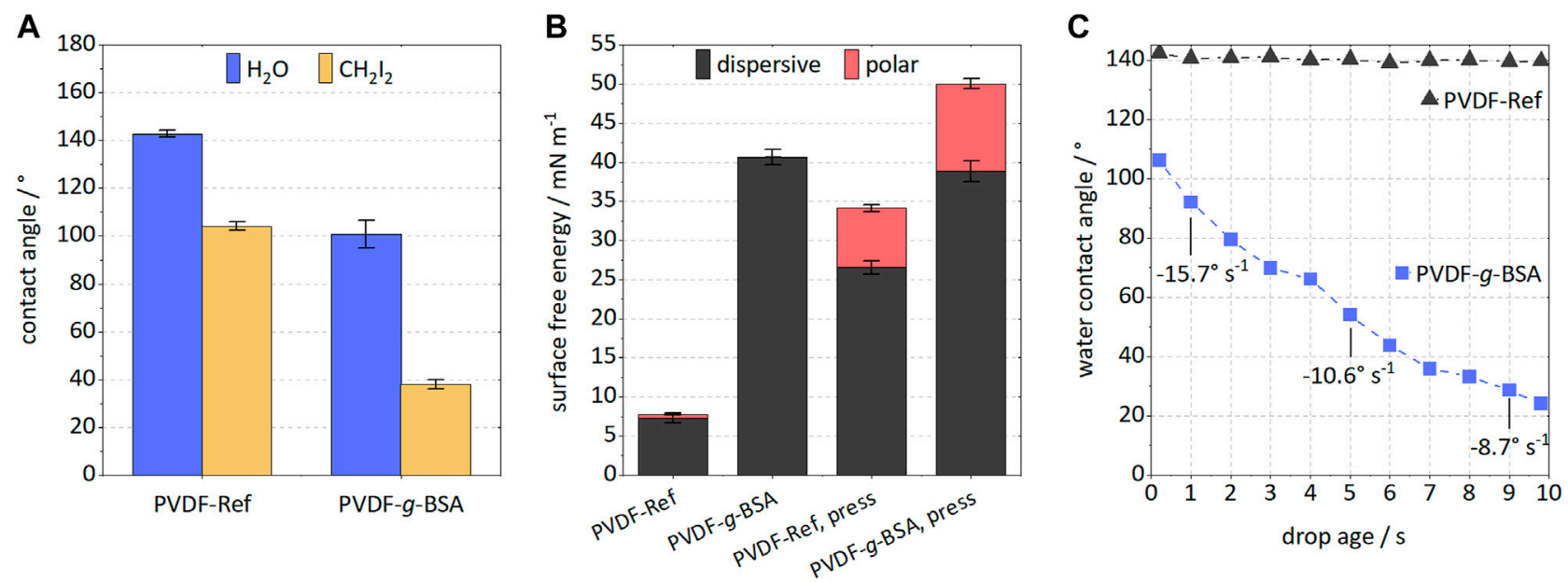

FIGURE 5 | Investigation of membrane surface hydrophilicity for PVDF-Ref and PVDF-g-BSA (optimized 1-step method). (A) contact angle measurement using water and $\mathrm{CH}_{2} \mathrm{I}_{2}$; (B) surface free energy with polar and dispersive components for raw and pressed samples; and (C) dynamic attenuation curve of water contact angle with drop age for BSA-grafted sample (given are three decay rates of contact angle referred to the initial value). Please note, the reference showed no change in contact angle within $10 \mathrm{~s}$.

BSA grafting yield of this study $\left(1,374 \mathrm{mg} \mathrm{m}^{-2}\right)$ is the highest reported GY so far. Interestingly, by calculating the GY per reaction time, the optimized 1 -step method reached up to 230 -fold higher efficiency $\left(19,100 \mathrm{mg} \mathrm{m}^{-2} \mathrm{~h}^{-1}\right)$ than the best literature procedure that could be found $\left(83 \mathrm{mg} \mathrm{m}^{-2} \mathrm{~h}^{-1}\right.$ via $500 \mathrm{mg} \mathrm{m}^{-2}$ within $6 \mathrm{~h}$ reaction time (Fang et al., 2010). Thus, excellent efficiency and effectivity of this advanced immobilization method was demonstrated.

Polymer characterizations revealed distinct improvements of the grafted samples. The static water contact angle decreased from $142.8^{\circ}$ to $100.8^{\circ}$ (Figure 5A). By using water and diiodomethane, respectively, surface free energies (SFE) could be calculated (Figure 5B). The BSA immobilization increased the overall SFE, rendering this modification to be promising for filtration applications or biomedical usage. Interestingly, mostly the dispersive part of the SFE raised corresponding to increased weak interactions. By minimizing effects of surface roughness and porosity via pressing the samples at high pressure, it was revealed that the polar part of SFE increased slightly. Since the polar SFE component corresponds to strong interactions due to localized shifts in electron density, a higher dispersive component could be more desirable for water filtration applications since electrostatically induced fouling might be reduced (Breite et al., 2015; Breite et al., 2016). Dynamic attenuation curves of water contact angles are often used as a measure of surface hydrophilicity to mitigate effects of surface roughness, capillary forces, or contraction in the dried state, respectively. A delayed water intake and thus, contact angle reduction, was monitored for the BSA grafted sample (Figure 5C). Within $10 \mathrm{~s}$ the contact angle decreased from $106^{\circ}$ to $24^{\circ}$, suggesting that the hydrophilicity of PVDF membrane was improved significantly. An initial decay rate of $-15.7^{\circ} \mathrm{s}^{-1}$ was determined, which, however, declines with time. An improved filtration performance can be expected due to stabilized long-term hydrophilization of the membrane surface.

Zeta potential and FTIR measurements indicated alterations of the PVDF surface chemistry. There are changes in the overall zeta potential curves (Figure 6A), e.g., at $\mathrm{pH}<8$ the zeta potential was shifted to higher values, and below $\mathrm{pH} 5.5$, the zeta potential is even net positive. In addition, the isoelectric point (IEP) shifted from 3.78 to 5.74 (top side), and from 3.82 to 5.34 (bottom side), respectively. Thus, the surface charge became more positive overall as a result of BSA immobilization, and the zeta potential curves indicated an amphoteric behavior of the modified membranes. Pristine PVDF is known to have an acidic IEP due to adsorption of $\mathrm{OH}^{-}$in water (Zimmermann et al., 2001). For the FTIR spectra of PVDF- $g$-BSA, the newly emerging peaks at 1,654 and $1,534 \mathrm{~cm}^{-1}$ indicate the presence of amide groups corresponding to the amide I $(\mathrm{O}=\mathrm{C}-\mathrm{N}-\mathrm{H})$ stretch vibrations and amide II $(\mathrm{N}-\mathrm{H})$ vibrations, which suggests that BSA was grafted successfully onto the surface of the PVDF membrane. Furthermore, a broad peak appeared at $3,300 \mathrm{~cm}^{-1}$ which was due to the $\mathrm{N}-\mathrm{H}$ of the amino group in BSA (Figure 6B).

Investigations of mechanical membrane properties revealed that EB irradiation (hence, the RIGI process) does not impact the overall stability of the samples. It is known that ionizing radiation can induce degradation and cross-linking reactions within fluoropolymers (Lyons, 1995; Forsythe and Hill, 2000; Dargaville et al., 2003). However, since RIGI utilizes aqueous impregnated membranes, the deposited energy via irradiation might be better attenuated by the water molecules acting as a kind of degradation protection. Tensile testing was performed to evaluate Young's modulus (E) and tensile strength $\left(\mathrm{F}_{\mathrm{r}}\right)$. PVDF-Ref yielded $\mathrm{E}=(165 \pm 11) \mathrm{N} \mathrm{mm}^{-2}$ and $\mathrm{F}_{\mathrm{r}}=(1.24 \pm 0.04) \mathrm{N}$, while PVDF- $g$-BSA yielded $\mathrm{E}=(159 \pm 13) \mathrm{N} \mathrm{mm}^{-2}$ and $\mathrm{F}_{\mathrm{r}}=(1.33 \pm 0.16)$ $\mathrm{N}$, respectively. Thus, tensile testing confirmed that the mechanical properties were not affected by the irradiation-based immobilization. Mercury intrusion porosimetry showed similar 

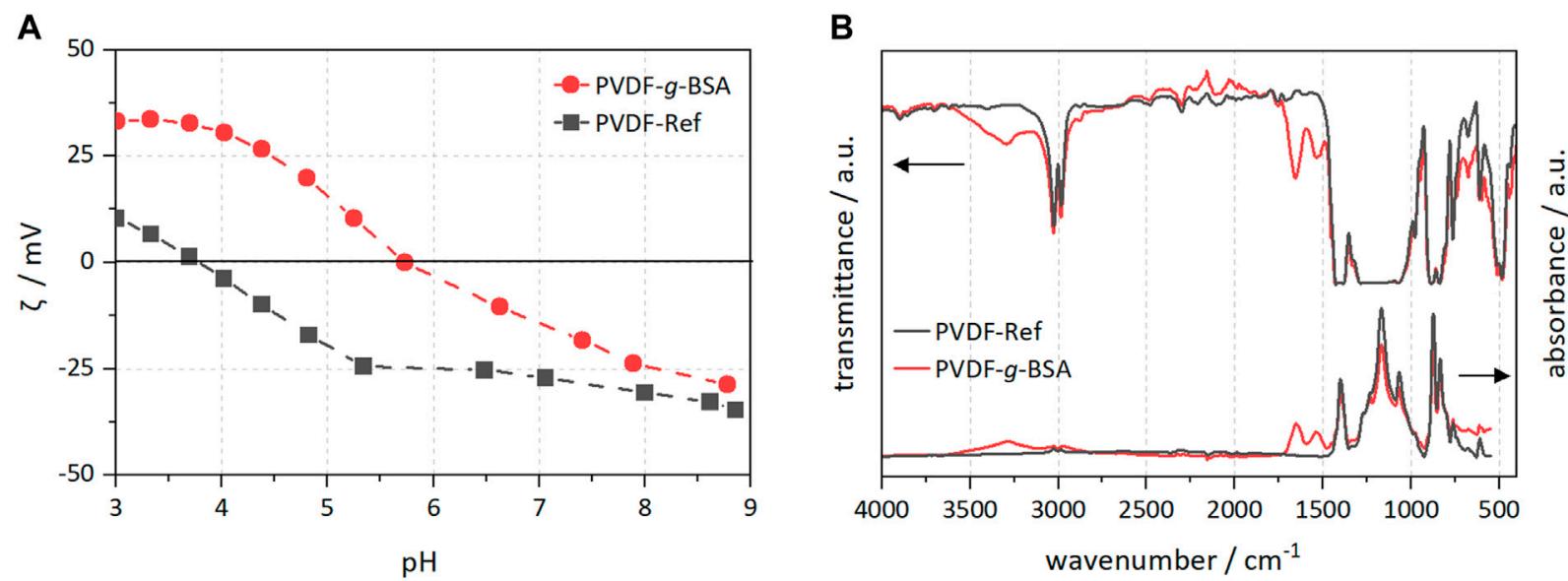

FIGURE 6 | PVDF surface characterization of modified and reference samples. (A) Zeta potential measurements; and (B) FTIR spectra in transmission and ATR mode.

porosity of $54.7 \pm 5.0 \%$ vs $51.7 \pm 1.5 \%$, for PVDF-Ref $v s$ PVDF- $g$ $\mathrm{BSA}$, respectively. Mean pore of grafted membrane (0.68 \pm $0.04 \mu \mathrm{m})$ was slightly higher than reference $(0.53 \pm 0.03 \mu \mathrm{m})$, however, this might be attributable to inhomogeneities in the employed membrane. Permeance examination of PVDF-Ref $\left(21,452 \pm 143 \mathrm{~L} \mathrm{~m}^{-2} \mathrm{~h}^{-1} \mathrm{bar}^{-1}\right)$ and PVDF- $g$-BSA (20,258 \pm $841 \mathrm{~L} \mathrm{~m}^{-2} \mathrm{~h}^{-1} \mathrm{bar}^{-1}$ ) showed only minimal reduction of permeance without practical relevance, i.e., an excellent filtration performance is maintained. Finally, scanning electron microscopy (SEM) confirmed that no changes in morphology, as well as only minimal clogging occurred during the treatment (Supplementary Figures S7, S8 in SI).

\section{CONCLUSION}

In this study, the model protein BSA was covalently coupled on PVDF polymer flat sheet membranes using an advanced radiation-induced graft immobilization (RIGI) procedure. This method utilizes solely an aqueous impregnated membrane and electron beam (EB) irradiation in order to cleanly and directly obtain grafted polymer materials. No additional chemicals such as coupling reagents, photoinitiators, catalysts, or organic solvents are needed, rendering this processing strategy as overall environmentally-friendly, safe and thus "green." Furthermore, this approach is technologically relevant due to its potential for simple scale-up and the possibility of a continuous mode of operation. By applying a statistical Design of Experiments (DoE) approach, nine process parameters were investigated in terms of their importance for achieving high grafting yields and homogeneity. Four factors are highly significant, i.e., BSA concentration, impregnation method and time, as well as irradiation dose. Subsequently, a process optimization using the response surface methodology (RSM) was performed resulting in a mathematical model for both, a commonly used 2-steps method and an improved 1-step method. The latter combines the impregnation step with a pre-wetting step, which is necessary for hydrophobic membranes such as PVDF. For the 1-step method, a BSA GY of $955 \mathrm{mg} \mathrm{m}^{-2} \pm 3.6 \%$ was already obtained for a BSA mass concentration of $11.5 \mathrm{~g} \mathrm{~L}^{-1}$, an impregnation time of $2.7 \mathrm{~min}$, and a dose of $117 \mathrm{kGy}$. The average BSA surface coverage was $78.3 \%$. Successful grafting was confirmed via BCA protein quantification, XPS, FTIR, contact angle and zeta potential measurements, respectively. Furthermore, since this immobilization method does not use additional chemicals, the impregnation solution can be reused multiple times, which was demonstrated to result in a very high efficiency of reproducing $\approx 100 \%$ grafting yield after five consecutive cycles. The highest determined BSA GY of this study $\left(1,374 \mathrm{mg} \mathrm{m}^{-2}\right)$ is the highest reported graft yield so far. Furthermore, this is accompanied by a 230 -fold higher efficiency $\left(19,100 \mathrm{mg} \mathrm{m}^{-2} \mathrm{~h}^{-1}\right)$ than the best literature procedure which is $83 \mathrm{mg} \mathrm{m}^{-2} \mathrm{~h}^{-1}$ via $500 \mathrm{mg} \mathrm{m}^{-2}$ in $6 \mathrm{~h}$ reaction time. Thus, excellent efficiency and effectivity of this advanced immobilization method was demonstrated. These results indicate that the modified PVDF membranes can be used in biomedical applications as well as in water treatment applications. Finally, this study proofs that the RIGI procedure can be applied for immobilization of proteins, peptides, or other molecules having more biological relevance while using a cleaner, more efficient and cheaper production.

\section{DATA AVAILABILITY STATEMENT}

The original contributions presented in the study are included in the article/Supplementary Material, further inquiries can be directed to the corresponding author.

\section{AUTHOR CONTRIBUTIONS}

Conceptualization, MS and AS; methodology, MS; software, MS; formal analysis, MS; investigation, MS, AA, and AP; 
resources, AS; data curation, MS; writing-original draft preparation, MS; writing-review and editing, MS, RG, and AS; visualization, MS; supervision, AS; project administration, MS; funding acquisition, MS. All authors have read and agreed to the published version of the manuscript.

\section{FUNDING}

This work was supported by Deutsche Bundesstiftung Umwelt (DBU) (20018/547).

\section{REFERENCES}

Ahmad Khairuddin, N. M., Muhammad Afifi, A., Hashim, N. A., Mohamad, S. E., and Kalantari, K. (2018). Immobilization of Bovine Serum Albumin on the Chitosan/PVA Film. Jsm 47, 1311-1318. doi:10.17576/jsm-20184706-28

Akashi, N., and Kuroda, S. (2015). Preparation and Characterization of Protein A-Immobilized PVDF and PES Membranes. Express Polym. Lett. 9, 2-13. doi:10.3144/expresspolymlett.2015.2

Albert, R., and Horwitz, W. (1997). A Heuristic Derivation of the Horwitz Curve. Anal. Chem. 69, 789-790. doi:10.1021/ac9608376

Anderson, M. J., and Whitcomb, P. J. (2010). "Design of Experiments," in Kirk-Othmer Encyclopedia of Chemical Technology. Editors R. E. Kirk and D. F. Othmer (Geneva: Interscience Publishers). doi:10.1002/ 0471238961.0405190908010814.a01.pub3

Bhattacharya, S., and Sasmal, M. (2016). Immobilization of Bovine Serum Albumin upon Multiwall Carbon Nanotube for High Speed Humidity Sensing Application. IEEE Trans.on Nanobioscience 15, 27-33. doi:10.1109/tnb.2015.2511622

Bi, S., Sun, Y., Qiao, C., Zhang, H., and Liu, C. (2009). Binding of Several Antitumor Drugs to Bovine Serum Albumin: Fluorescence Study. J. Lumin. 129, 541-547. doi:10.1016/j.jlumin.2008.12.010

Blauer, G., and King, T. E. (1970). Interactions of Bilirubin with Bovine Serum Albumin in Aqueous Solution. J. Biol. Chem. 245, 372-381. doi:10.1016/ s0021-9258(18)63402-7

Bobrowski, K. (2017). "Radiation Chemistry of Liquid Systems," in Applications of Ionizing Radiation in Materials Processing. Editors Y. Sun and A.G. Chmielewski (Warszawa: Institute of Nuclear Chemistry and Technology).

Box, G. E. P., and Wilson, K. B. (1951). On the Experimental Attainment of Optimum Conditions. J. R. Stat. Soc. Ser. B (Methodological) 13, 1-38. doi:10.1111/j.2517-6161.1951.tb00067.x

Breite, D., Went, M., Prager, A., and Schulze, A. (2015). Tailoring Membrane Surface Charges: A Novel Study on Electrostatic Interactions during Membrane Fouling. Polymers 7, 2017-2030. doi:10.3390/polym7101497

Breite, D., Went, M., Thomas, I., Prager, A., and Schulze, A. (2016). Particle Adsorption on a Polyether Sulfone Membrane: How Electrostatic Interactions Dominate Membrane Fouling. RSC Adv. 6, 65383-65391. doi:10.1039/c6ra13787c

Buonomenna, M. G., and Bae, J. (2014). Organic Solvent Nanofiltration in Pharmaceutical Industry. Separat. Purif. Rev. 44, 157-182. doi:10.1080/ 15422119.2014.918884

Buxton, G. V., Greenstock, C. L., Helman, W. P., and Ross, A. B. (1988). Critical Review of Rate Constants for Reactions of Hydrated Electrons, Hydrogen Atoms and Hydroxyl Radicals (.OH/.O- in Aqueous Solution. J. Phys. Chem. Reference Data 17, 513-886. doi:10.1063/1.555805

Casimiro, M. H., Ferreira, L. M., Leal, J. P., Pereira, C. C. L., and Monteiro, B. (2019). Ionizing Radiation for Preparation and Functionalization of Membranes and Their Biomedical and Environmental Applications. Membranes 9, 163-181. doi:10.3390/membranes9120163

\section{ACKNOWLEDGMENTS}

The financial support by the Federal State of Germany and the Free State of Saxony is gratefully acknowledged. Nadja Schönherr is greatly acknowledged for performing the FTIR measurements.

\section{SUPPLEMENTARY MATERIAL}

The Supplementary Material for this article can be found online at: https://www.frontiersin.org/articles/10.3389/fchem.2021.804698/ full\#supplementary-material

Chung, Y. T., Ng, L. Y., and Mohammad, A. W. (2014). Sulfonatedpolysulfone Membrane Surface Modification by Employing Methacrylic Acid through UV-Grafting: Optimization through Response Surface Methodology Approach. J. Ind. Eng. Chem. 20, 1549-1557. doi:10.1016/j.jiec.2013.07.046

Dargaville, T. R., George, G. A., Hill, D. J. T., and Whittaker, A. K. (2003). High Energy Radiation Grafting of Fluoropolymers. Prog. Polym. Sci. 28, 1355-1376. doi:10.1016/s0079-6700(03)00047-9

Das, S., Islam, M. M., Jana, G. C., Patra, A., Jha, P. K., and Hossain, M. (2017). Molecular Binding of Toxic Phenothiazinium Derivatives, Azures to Bovine Serum Albumin: A Comparative Spectroscopic, Calorimetric, and In Silico Study. J. Mol. Recognit 30, e2609. doi:10.1002/jmr.2609

Derringer, G., and Suich, R. (2018). Simultaneous Optimization of Several Response Variables. J. Qual. Technol. 12, 214-219. doi:10.1080/ 00224065.1980 .11980968

Eş, I., Vieira, J. D. G., and Amaral, A. C. (2015). Principles, Techniques, and Applications of Biocatalyst Immobilization for Industrial Application. Appl. Microbiol. Biotechnol. 99, 2065-2082. doi:10.1007/s00253-0156390-y

Fang, B., Cheng, C., Li, L., Cheng, J., Zhao, W., and Zhao, C. (2010). Surface Modification of Polyethersulfone Membrane by Grafting Bovine Serum Albumin. Fibers Polym. 11, 960-966. doi:10.1007/s12221-010-0960-5

Fang, B., Ling, Q., Zhao, W., Ma, Y., Bai, P., Wei, Q., et al. (2009). Modification of Polyethersulfone Membrane by Grafting Bovine Serum Albumin on the Surface of Polyethersulfone/poly(acrylonitrile-Co-Acrylic Acid) Blended Membrane. J. Membr. Sci. 329, 46-55. doi:10.1016/j.memsci.2008.12.008

Feng, C. Y., Khulbe, K. C., Matsuura, T., and Ismail, A. F. (2013). Recent Progresses in Polymeric Hollow Fiber Membrane Preparation, Characterization and Applications. Separat. Purif. Technol. 111, 43-71. doi:10.1016/j.seppur.2013.03.017

Forsythe, J. S., and Hill, D. J. T. (2000). The Radiation Chemistry of Fluoropolymers. Prog. Polym. Sci. 25, 101-136. doi:10.1016/s00796700(00)00008-3

Ganj, M., Asadollahi, M., Mousavi, S. A., Bastani, D., and Aghaeifard, F. (2019). Surface Modification of Polysulfone Ultrafiltration Membranes by Free Radical Graft Polymerization of Acrylic Acid Using Response Surface Methodology. J. Polym. Res. 26. doi:10.1007/s10965-019-1832-3

Gibbs, B. F., and Mulligan, C. N. (1997). Styrene Toxicity: An Ecotoxicological Assessment. Ecotoxicology Environ. Saf. 38, 181-194. doi:10.1006/ eesa.1997.1526

Horie, K., Barón, M., Fox, R. B., He, J., Hess, M., Kahovec, J., et al. (2004). Definitions of Terms Relating to Reactions of Polymers and to Functional Polymeric Materials (IUPAC Recommendations 2003). Pure Appl. Chem. 76, 889-906. doi:10.1351/pac200476040889

Jahangiri, E., Reichelt, S., Thomas, I., Hausmann, K., Schlosser, D., and Schulze, A. (2014). Electron Beam-Induced Immobilization of Laccase on Porous Supports for Waste Water Treatment Applications. Molecules 19, 11860-11882. doi:10.3390/molecules 190811860

Kang, G.-D., and Cao, Y.-M. (2014). Application and Modification of Poly(vinylidene Fluoride) (PVDF) Membranes - A Review. J. Membr. Sci. 463, 145-165. doi:10.1016/j.memsci.2014.03.055 
Kang, I.-K., Kwon, B. K., Lee, J. H., and Lee, H. B. (1993). Immobilization of Proteins on Poly(methyl Methacrylate) Films. Biomaterials 14, 787-792. doi:10.1016/0142-9612(93)90045-4

Kato, K., Uchida, E., Kang, E.-T., Uyama, Y., and Ikada, Y. (2003). Polymer Surface with Graft Chains. Prog. Polym. Sci. 28, 209-259. doi:10.1016/s0079-6700(02) 00032-1

Kochkodan, V. M., and Sharma, V. K. (2012). Graft Polymerization and Plasma Treatment of Polymer Membranes for Fouling Reduction: a Review. J. Environ. Sci. Health A 47, 1713-1727. doi:10.1080/10934529.2012.689183

Ladavière, C., Delair, T., Domard, A., Pichot, C., and Mandrand, B. (1999). Covalent Immobilization of Bovine Serum Albumin onto (Maleic Anhydride-Alt-Methyl Vinyl Ether) Copolymers. J. Appl. Polym. Sci. 72, 1565-1572. doi:10.1002/(sici)1097-4628(19990620)72:12<1565:Aidapp9>3.0.Co;2-n

Li, C., Jin, J., Liu, J., Xu, X., and Yin, J. (2014). Improving Hemocompatibility of Polypropylene via Surface-Initiated Atom Transfer Radical Polymerization for Covalently Coupling BSA. RSC Adv. 4, 24842-24851. doi:10.1039/c4ra03652b

Liu, F., Hashim, N. A., Liu, Y., Abed, M. R. M., and Li, K. (2011). Progress in the Production and Modification of PVDF Membranes. J. Membr. Sci. 375, 1-27. doi:10.1016/j.memsci.2011.03.014

Liu, Z., Deng, X., Wang, M., Chen, J., Zhang, A., Gu, Z., et al. (2012). BSA-modified Polyethersulfone Membrane: Preparation, Characterization and Biocompatibility. J. Biomater. Sci. Polym. Edition 20, 377-397. doi:10.1163/ $156856209 \times 412227$

Lyons, B. J. (1995). Radiation Crosslinking of Fluoropolymers-A Review. Radiat. Phys. Chem. 45, 159-174. doi:10.1016/0969-806x(94)e0002-z

Madrid, J. F., Lopez, G. E. P., and Abad, L. V. (2017). Application of Full-Factorial Design in the Synthesis of Polypropylene-G-Poly(glycidyl Methacrylate) Functional Material for Metal Ion Adsorption. Radiat. Phys. Chem. 136, 54-63. doi:10.1016/j.radphyschem.2017.01.047

Majorek, K. A., Porebski, P. J., Dayal, A., Zimmerman, M. D., Jablonska, K., Stewart, A. J., et al. (2012). Structural and Immunologic Characterization of Bovine, Horse, and Rabbit Serum Albumins. Mol. Immunol. 52, 174-182. doi:10.1016/j.molimm.2012.05.011

Mandal, D. K., Bhunia, H., Bajpai, P. K., Kushwaha, J. P., Chaudhari, C. V., Dubey, K. A., et al. (2017). Optimization of Acrylic Acid Grafting onto Polypropylene Using Response Surface Methodology and its Biodegradability. Radiat. Phys. Chem. 132, 71-81. doi:10.1016/ j.radphyschem.2016.12.003

Mayuri, P. V., Bhatt, A., and Parameswaran, R. (2020). Investigation of the Potency of Leukodepletion Filter Membranes Immobilized with Bovine Serum Albumin via Polydopamine Spacer. SN Appl. Sci. 2, 1738. doi:10.1007/s42452-020-03515-2

Mollahosseini, A., Abdelrasoul, A., and Shoker, A. (2020). A Critical Review of Recent Advances in Hemodialysis Membranes Hemocompatibility and Guidelines for Future Development. Mater. Chem. Phys. 248, 122911. doi:10.1016/j.matchemphys.2020.122911

Müller, A., Preuss, A., Bornhütter, T., Thomas, I., Prager, A., Schulze, A., et al. (2018). Electron Beam Functionalized Photodynamic Polyethersulfone Membranes - Photophysical Characterization and Antimicrobial Activity. Photochem. Photobiol. Sci. 17, 1346-1354. doi:10.1039/c8pp00254a

Nasef, M. M., Ahmad Ali, A., Saidi, H., and Ahmad, A. (2014). Modeling and Optimization Aspects of Radiation Induced Grafting of 4-vinylpyridene onto Partially Fluorinated Films. Radiat. Phys. Chem. 94, 123-128. doi:10.1016/ j.radphyschem.2013.05.049

Nasef, M. M., Aly, A. A., Saidi, H., and Ahmad, A. (2011). Optimization of Reaction Parameters of Radiation Induced Grafting of 1-vinylimidazole onto Poly(ethylene-Co-Tetraflouroethene) Using Response Surface Method. Radiat. Phys. Chem. 80, 1222-1227. doi:10.1016/j.radphyschem.2011.06.014

Nasef, M. M., Shamsaei, E., Ghassemi, P., Aly, A. A., and Yahaya, A. H. (2013). Modeling, Prediction, and Multifactorial Optimization of Radiation-Induced Grafting of 4-vinylpyridine onto Poly(vinylidene Fluoride) Films Using Statistical Simulator. J. Appl. Polym. Sci. 127, 1659-1666. doi:10.1002/ app. 37558

Nasef, M. M., Shamsaei, E., Ghassemi, P., Aly, A. A., and Yahaya, A. H. (2012). Optimization Strategies for Radiation Induced Grafting of 4-vinylpyridine onto Poly(ethylene-Co-Tetraflouroethene) Film Using Box-Behnken Design. Radiat. Phys. Chem. 81, 437-444. doi:10.1016/j.radphyschem.2011.12.019
Nasef, M. (2004). Preparation and Applications of Ion Exchange Membranes by Radiation-Induced Graft Copolymerization of Polar Monomers onto Nonpolar Films. Prog. Polym. Sci. 29, 499-561. doi:10.1016/ j.progpolymsci.2004.01.003

Owens, D. K., and Wendt, R. C. (1969). Estimation of the Surface Free Energy of Polymers. J. Appl. Polym. Sci. 13, 1741-1747. doi:10.1002/ app.1969.070130815

Pendergast, M. M., and Hoek, E. M. V. (2011). A Review of Water Treatment Membrane Nanotechnologies. Energy Environ. Sci. 4, 1946-1971. doi:10.1039/ c0ee00541j

Ramos-Ballesteros, A., Pino-Ramos, V. H., López-Saucedo, F., Flores-Rojas, G. G., and Bucio, E. (2019). " $\gamma$-Rays and Ions Irradiation," in Surface Modification of Polymers. Editors J. Pinson and D. Thiry (Weinheim: Wiley VCH), 185-209. doi:10.1002/9783527819249.ch7

Reinhardt, A., Thomas, I., Schmauck, J., Giernoth, R., Schulze, A., and Neundorf, I. (2018). Electron Beam Immobilization of Novel Antimicrobial, Short Peptide Motifs Leads to Membrane Surfaces with Promising Antibacterial Properties. Jfb 9, 21-31. doi:10.3390/jfb9010021

Riyasudheen, N., Binsy, P., Aswini, K. K., Jayadevan, J., and Athiyanathil, S. (2012). Bovine Serum Albumin Immobilized-Polyvinyl Alcohol Membranes: A Study Based on Sorption, Dye Release and Protein Adsorption. Polymer-Plastics Technol. Eng. 51, 1351-1354. doi:10.1080/03602559.2012.702254

Samuel, A. H., and Magee, J. L. (1953). Theory of Radiation Chemistry. II. Track Effects in Radiolysis of Water. J. Chem. Phys. 21, 1080-1087. doi:10.1063/ 1.1699113

Schmidt, M., Breite, D., Thomas, I., Went, M., Prager, A., and Schulze, A. (2018). Polymer Membranes for Active Degradation of Complex Fouling Mixtures. J. Membr. Sci. 563, 481-491. doi:10.1016/j.memsci.2018.06.013

Schmidt, M., Zahn, S., Gehlhaar, F., Prager, A., Griebel, J., Kahnt, A., et al. (2021). Radiation-Induced Graft Immobilization (RIGI): Covalent Binding of Nonvinyl Compounds on Polymer Membranes. Polymers 13, 1849. doi:10.3390/ polym 13111849

Schulze, A., Breite, D., Kim, Y., Schmidt, M., Thomas, I., Went, M., et al. (2017). Bio-Inspired Polymer Membrane Surface Cleaning. Polymers 9, 97-106. doi:10.3390/polym9030097

Schulze, A., Maitz, M. F., Zimmermann, R., Marquardt, B., Fischer, M., Werner, C., et al. (2013). Permanent Surface Modification by Electron-Beam-Induced Grafting of Hydrophilic Polymers to PVDF Membranes. RSC Adv. 3, 22518-22526. doi:10.1039/c3ra43659d

Schulze, A., Marquardt, B., Kaczmarek, S., Schubert, R., Prager, A., and Buchmeiser, M. R. (2010). Electron Beam-Based Functionalization of Poly(ethersulfone) Membranes. Macromol. Rapid Commun. 31, 467-472. doi:10.1002/marc.200900666

Schulze, A., Marquardt, B., Went, M., Prager, A., and Buchmeiser, M. R. (2012). Electron Beam-Based Functionalization of Polymer Membranes. Water Sci. Technol. 65, 574-580. doi:10.2166/wst.2012.890

Smith, P. K., Krohn, R. I., Hermanson, G. T., Mallia, A. K., Gartner, F. H., Provenzano, M. D., et al. (1985). Measurement of Protein Using Bicinchoninic Acid. Anal. Biochem. 150, 76-85. doi:10.1016/00032697(85)90442-7

Starke, S., Went, M., Prager, A., and Schulze, A. (2013). A Novel Electron Beam-Based Method for the Immobilization of Trypsin on Poly(ethersulfone) and Poly(vinylidene Fluoride) Membranes. Reactive Funct. Polym. 73, 698-702. doi:10.1016/j.reactfunctpolym.2013.02.013

Subasi, Y., and Cicek, B. (2017). Recent Advances in Hydrophilic Modification of PVDF Ultrafiltration Membranes - a Review: Part I. Membr. Technol. 2017, 7-12. doi:10.1016/s0958-2118(17)30191-x

Suh, M., Proctor, D., Chappell, G., Rager, J., Thompson, C., Borghoff, S., et al. (2018). A Review of the Genotoxic, Mutagenic, and Carcinogenic Potentials of Several Lower Acrylates. Toxicology 402-403, 50-67. doi:10.1016/j.tox.2018.04.006

Sutherland, K. (2004). Profile of the International Membrane Industry: Market Prospects to 2008. Oxford: Elsevier Advanced Technology.

Szymczyk, A., Van Der Bruggen, B., and Ulbricht, M. (2019). "Surface Modification of Water Purification Membranes," in Surface Modification of Polymers. Editors J. Pinson and D. Thiry (Weinheim: Wiley VCH), 363-398. doi:10.1002/ 9783527819249.ch13

Ulbricht, M. (2006). Advanced Functional Polymer Membranes. Polymer 47, 2217-2262. doi:10.1016/j.polymer.2006.01.084 
Ulbricht, M., and Riedel, M. (1998). Ultrafiltration Membrane Surfaces with Grafted Polymer 'tentacles': Preparation, Characterization and Application for Covalent Protein Binding. Biomaterials 19, 1229-1237. doi:10.1016/s0142-9612(98)00029-5

Vatanpour, V., and Sanadgol, A. (2020). Surface Modification of Reverse Osmosis Membranes by Grafting of Polyamidoamine Dendrimer Containing Graphene Oxide Nanosheets for Desalination Improvement. Desalination 491, 114442. doi:10.1016/j.desal.2020.114442

Vitola, G., Mazzei, R., Fontananova, E., and Giorno, L. (2015). PVDF Membrane Biofunctionalization by Chemical Grafting. J. Membr. Sci. 476, 483-489. doi:10.1016/j.memsci.2014.12.004

Wang, D., Li, B., Zhao, W., Lu, Y., Sun, S., and Zhao, C. (2012). Protein-grafted Carboxylic Poly(ether Sulfone) Membranes: Preparation and Characterization. J. Appl. Polym. Sci. 126, 1277-1290. doi:10.1002/app.36630

Whitcomb, P., and Anderson, M. "Screening Process Factors in the Presence of Interactions," in Proceedings of the 58th Annual Quality Congress, Toronto, ON, Canada, May 2004 (Milwaukee: American Society for Quality).

Wu, K., Song, X., Cui, S., Li, Z., Jiao, Y., and Zhou, C. (2018). Immobilization of Bovine Serum Albumin via Mussel-Inspired Polydopamine Coating on Electrospun Polyethersulfone (PES) Fiber Mat for Effective Bilirubin Adsorption. Appl. Surf. Sci. 451, 45-55. doi:10.1016/j.apsusc.2018.04.242

Wu, L., Sun, J., and Tong, F. (2014). Surface Modification of a PVDF Membrane by Cross-Linked Collagen. RSC Adv. 4, 63989-63996. doi:10.1039/c4ra08203f

Yiğitoğlu, M., Işıklan, N., and Özmen, R. (2007). Graft Copolymerization ofNVinyl-2-Pyrrolidone onto Sodium Carboxymethylcellulose with Azobisisobutyronitrile as the Initiator. J. Appl. Polym. Sci. 104, 936-943. doi: $10.1002 /$ app. 25786

Zeng, X., and Ruckenstein, E. (1999). Membrane Chromatography: Preparation and Applications to Protein Separation. Biotechnol. Prog. 15, 1003-1019. doi:10.1021/bp990120e
Zhang, C., Jin, J., Zhao, J., Jiang, W., and Yin, J. (2013). Functionalized Polypropylene Non-woven Fabric Membrane with Bovine Serum Albumin and its Hemocompatibility Enhancement. Colloids Surf. B: Biointerfaces 102, 45-52. doi:10.1016/j.colsurfb.2012.08.007

Zhu, L.-P., Jiang, J.-H., Zhu, B.-K., and Xu, Y.-Y. (2011). Immobilization of Bovine Serum Albumin onto Porous Polyethylene Membranes Using Strongly Attached Polydopamine as a Spacer. Colloids Surf. B: Biointerfaces 86, 111-118. doi:10.1016/j.colsurfb.2011.03.027

Zimmermann, R., Dukhin, S., and Werner, C. (2001). Electrokinetic Measurements Reveal Interfacial Charge at Polymer Films Caused by Simple Electrolyte Ions. J. Phys. Chem. B 105, 8544-8549. doi:10.1021/ jp004051u

Conflict of Interest: The authors declare that the research was conducted in the absence of any commercial or financial relationships that could be construed as a potential conflict of interest.

Publisher's Note: All claims expressed in this article are solely those of the authors and do not necessarily represent those of their affiliated organizations, or those of the publisher, the editors, and the reviewers. Any product that may be evaluated in this article, or claim that may be made by its manufacturer, is not guaranteed or endorsed by the publisher.

Copyright (C) 2022 Schmidt, Abdul Latif, Prager, Gläser and Schulze. This is an openaccess article distributed under the terms of the Creative Commons Attribution License (CC BY). The use, distribution or reproduction in other forums is permitted, provided the original author(s) and the copyright owner(s) are credited and that the original publication in this journal is cited, in accordance with accepted academic practice. No use, distribution or reproduction is permitted which does not comply with these terms. 